\title{
TOPÓNIMOS Y CRONOLOGÍA: NOTAS SOBRE UNA PUERTA DISTINTA AL ESTUDIO DEL PASADO
}

\author{
Brígida von Mentz \\ Centro de Investigaciones y Estudios Superiores \\ en Antropología Social
}

$\mathrm{C}_{\mathrm{y} \text { el diálogo con lingüistas puede abrir puertas al estu- }}^{\mathrm{n} \text { este ensayo se propone que el análisis de topónimos }}$ dio del México antiguo premexica, época que, por razones vinculadas a las fuentes, ha quedado marginada en la academia del estudio de la historia propiamente dicha, permaneciendo calificada como "prehistoria." Historiadores y lingüistas comparten la dificultad de explicar movimientos de población ocurridos en épocas lejanas, para los que faltan evidencias documentales; a la vez, ambas disciplinas se interesan en explicar temas como conquistas en tiempos remotos, migraciones, vínculos comerciales a larga distancia, existencia de enclaves culturales en distintas zonas, entre muchos otros más. Ante esas coincidencias, se propone tentativamente en este trabajo que los topónimos, en tanto registros históricos distintos a las evidencias documentales, pueden ser un tema compartido por las dos disciplinas, ade-

Fecha de recepción: 9 de octubre de 2015

Fecha de aceptación: 20 de abril de 2016 
más de que su análisis puede satisfacer una natural curiosidad de por qué un lugar se nombra de determinada manera. ${ }^{1}$

Se argumentará primero, a partir de ejemplos europeos y mexicanos, la utilidad generalizada que han tenido los estudios de nombres de lugares para escudriñar el pasado de distintas sociedades. Después se verá cómo el análisis de los nombres indígenas de lugares de Mesoamérica que se han conservado gracias a que se fijaron por escrito en todo tipo de documentos puede ser una llave para arrojar algo de luz sobre épocas remotas; llave con la que el historiador puede abrir una puerta e intentar recorrer la línea temporal de manera inversa. A partir de más de 4000 topónimos en lengua indígena en el México colonial, que incluyen resultados de una investigación reciente que realicé sobre los chontales en el actual estado de Guerrero, cuya lengua desapareció en el siglo XviI, este artículo se propone hacer uso de los nombres de lugar para acercarnos a épocas prehispánicas. Específicamente se planteará de manera tentativa la posibilidad de explicar movimientos de hablantes de distintas variantes del náhuatl, en diversas épocas, a partir de ciertos topónimos de poblados que quizá muestran antiguas migraciones y conexiones comerciales que perduraron por largos periodos, así como también otros, que delatan colonizaciones imperiales mexicas. Primero, sin embargo, habrá que recordar algunos aspectos más generales vinculados al estudio de la toponimia.

\footnotetext{
1 No se abordará el tema de los topónimos en fuentes pictográficas, aunque es un campo en el que hay mucho que profundizar. Conlleva consideraciones de crítica de fuentes y de análisis epigráfico que por su amplitud no pueden abordarse en este ensayo. Para un estudio que los retoma a nivel regional, Mentz, Cuaubnabuac, capítulos 5 y 6 .
} 
LA MANERA DE NOMBRAR LUGARES:

ASPECTOS UNIVERSALES Y ASPECTOS ESPECÍFICOS

Los distintos pueblos nombran a sus poblados con frecuencia a partir de la descripción de los espacios que los rodean - los cerros, los ríos, los asentamientos, las regiones más amplias. Esto se expresa muchas veces en nombres descriptivos de características geográficas, orográficas, hidrológicas, entre otras. En todas partes abundan los Ríos Colorados o las Aguas Blancas, los Carrizales, las Ciénegas, las Lomas Grandes, los Cerros Redondos (en Escandinavia por ejemplo las “Islas Redondas” Tjock Ön), etc. Así encontramos también en Mesoamérica que se nombran en lengua nahua numerosos valles (Ixtlahuaca), o cerros grandes (Hueytepetl); también son numerosos los Atlamaxac, o Amaxac (lugar donde se dividen los ríos), las salinas se encuentran generalmente descritas por su nombre Ixtapan (istatl, sal) y lo que en castellano se denomina "Laguna Verde" se nombra en matlatzinca $P i$ - con-táwi, etc. Veremos algunos ejemplos más adelante, en el cuadro 1.

Otras maneras de nombrar un lugar hacen referencia con frecuencia a un grupo que vivió en determinada zona: Bohemia en Europa central se denominó así por los bohii que ahí moraban; Italia recibió el nombre de los italiotas que habitaban en el sur de la península; Zacatecas fue nombrado así por el grupo de los zacatecos que vivía en la zona, y en Chihuahua el río Conchos es un nombre que deriva de los indios denominados conchos, entre muchos otros ejemplos. En lengua nahua encontramos topónimos como Mexicapan (mexica y el locativo-pan), "lugar de los mexica"; se forman de la misma manera en Nayarit Cora-pan (cora y el locativo 
-pan), así como Matlapan (matlame y el locativo-pan), Chichimecapan (chichimeca-pan), Tepanecapan (tepaneca-pan) entre muchos otros, relacionados con los cora, los matlatzincas, chichimecas o tepanecas. ${ }^{2}$

En todos los hemisferios han destacado también nombres vinculados al comercio y a colonias comerciales o a migraciones. Son famosos a todo lo largo de la costa del Mediterráneo los topónimos fenicios (Gadez o Cádiz, Cartago) o griegos, y hay topónimos que remiten claramente a migraciones, pues cuando los pueblos fundan colonias crean nuevas designaciones para un lugar, y muchas veces emplean un nombre ya existente en el nuevo terruño. Por eso sin duda tiene razón el lingüista Guzmán Betancourt, quien opina en un estudio especializado sobre topónimos, que son por lo regular los "extranjeros" quienes suelen imponer y difundir el nuevo nombre, que en muchas ocasiones termina desterrando al autóctono, si lo hubo. ${ }^{3}$ Así, vemos en la actualidad que en Canadá existe un Berlín, en Texas un París, y también las denominaciones Nueva España, Nueva Galicia o Valladolid en Yucatán son testimonio de tales traslados. ${ }^{4}$

Conservar el nombre original o aceptar el nuevo está frecuentemente ligado a la calidad de las relaciones sociales y

2 Véase la obra de García Martínez y Martínez Mendoza, Señoríos, y los índices analíticos de las obras de TANCK, Atlas ilustrado; CARRASCO, Estructura, y Gerhard, Geografía histórica, entre otras obras.

${ }^{3}$ Guzmán, De toponimia, pp. 23-25.

${ }^{4}$ Guzmán menciona también nombres en México como Salamanca, Guadalajara, Córdoba entre otros y asimismo la existencia, sólo en el estado de Missouri, Estados Unidos, de Windsor, Lancaster, Stockton, New London, París, Versalles, Macon, New Madrid, Milán, Lebanon, etcétera. Guzmán, De toponimia, p. 24. 
políticas entre los nativos y los extranjeros que llegan. En Texas, por ejemplo, se impusieron los nombres de los colonos y los indios nativos fueron exterminados; en otros lugares multilingües rivalizan etnias y se lucha violentamente por cuál debe ser el nombre oficial de la aldea o ciudad, y las profundas contiendas políticas se expresan en la toponimia. Karl Anton Nowotny, etnólogo austriaco, se refería, por ejemplo, a las luchas políticas en Europa oriental en torno al nombre de la ciudad de Pozsony en donde durante tres siglos se coronaron los reyes húngaros; tan importante ciudad se conocía en alemán como Pressburg y en eslovaco como Bratislava. ${ }^{5}$ Así vemos que en muchos lugares del mundo los poblados suelen tener varios nombres, frecuentemente en lenguas distintas, según ha pasado el tiempo, y este trabajo subrayará este hecho y buscará aprovecharlo como evidencia histórica.

Precisamente la práctica de renombrar un lugar remite a una ocupación por parte de otro pueblo, y así ese hecho, o el que perdure un antiguo topónimo, ha permitido la realización de estudios históricos lingüísticos y la resolución de enigmas relacionados con pueblos que no dejaron registros escritos de su pasado, o que no se han descifrado. Un caso problemático fue, por ejemplo, el origen de los eslavos, difícil de escudriñar al no existir registros históricos escritos tempranos; éstos no se generaron sino hasta después de que llegaran a Europa central, cerca del siglo viI y viII y que fueran cristianizados. ${ }^{6}$ Para resolver el problema,

${ }^{5}$ Citado en Anders, Jansen, Reyes, “Introducción”, p. 36.

${ }^{6}$ Beekes, Comparative Indo-European Linguistics; Longworth, The Making of Eastern Europe. 
desde el siglo xix los historiadores analizaron los nombres de lugar en lengua eslava y así las huellas de esos topónimos en Asia, Rusia y el sureste europeo permitieron la reconstrucción de las rutas de migraciones eslavas. Se trataba de migraciones en distintas direcciones, y con esta metodología se pudo documentar la cronología en la que ocurrieron, pues en los márgenes de los ríos se pudieron registrar topónimos de origen eslavo desde mucho antes de sus arribos a Europa central, y también se pudo comprobar su presencia en el Peloponeso así como su parcial incorporación a los poblados griegos. ${ }^{7}$

Ese recurso histórico se ha seguido usando en épocas posteriores. El famoso historiador francés Marc Bloch usó el análisis toponímico en su historia rural de Francia y así se ha documentado la complejidad social y étnica del pasado de numerosos países. En Alemania, por ejemplo, se demuestra la numerosa presencia de etnias eslavas desde la temprana Edad Media gracias a poblados con nombres muy frecuentes terminados en -ow (Pankow, Gatow, Ratenow, todos cerca de Berlín) o terminados en -itz o -zig, como Leipzig, la actual metrópoli en Sajonia, o Steglitz, Lankwitz entre muchos otros. La numerosa toponimia con esa estructura morfológica revela la importancia de los distintos pueblos eslavos que forman parte de la historia alemana del este y que vivieron en amplios territorios que después fueron colonizados por campesinos de habla germana. ${ }^{8}$

\footnotetext{
7 Longworth, The Making of Eastern Europe, pp. 301-303. Para observar sus rutas migratorias entre 250 y 800 d.C., al este, sur, norte y oeste, véase en esa obra el mapa de la p. ix.

8 Es de interés cómo la historia política de los estados nacionales generalmente niega la complejidad etnohistórica de su pasado. Por ejemplo, en
} 
En el décimo siglo de nuestra era, y sobre todo en los siglos XI y XII, llegaron a las regiones al este del río Elba en Europa central campesinos de habla alemana (bajosajones, flamencos, entre otros). Arribaron a la actual Sajonia y a Bohemia tanto como colonos agricultores - que gozaban de privilegios de frontera- como mineros. ${ }^{9}$ Precisamente esa gran ola de migración hacia el oriente de colonos de habla germánica del occidente, procedentes de los Países Bajos y orillas del Rin, se refleja en la toponimia, que cronológicamente se puede fijar con exactitud como posterior al siglo x. Numerosos nombres están ligados a esa sistemática colonización, por ejemplo pueblos que abrieron terrenos mediante la rotura de bosques terminan en -rode (del verbo roden, rozar, talar árboles, abrir brechas). Por ejemplo, Wernigerode o el actual Osterode al sur de Hannover. También revelan vínculos con determinadas etnias germanas ciertas categorías de topónimos en Bavaria, por ejemplo, los terminados con (-ing, como Herrsching) o en Suabia (-ingen) o Turingia (-ungen). Estos últimos se refieren, con el sufijo -ingen o -ungen, a "aquellos que siguieron a fulano" o que "radican donde vive fulano", por ejemplo, al sur de la actual ciudad de Stuttgart, Sigmaringen

Alemania los eslavos al este son marginados de la historia (con excepción de la época de la República Democrática Alemana, que los reivindicó). No fue sino hasta que el literato y premio nobel Günther Grass mencionó la presencia de los cashubii en las orillas polacogermanas del mar Báltico, en su obra El tambor de hojalata, que ese pueblo entró en la conciencia generalizada de lo complejo que es el origen de lo llamado "alemán".

${ }_{9}$ Los privilegios de frontera de que gozaban estos colonos agricultores germanoparlantes recuerdan a los de los tlaxcaltecas y otros colonos indígenas en el proceso de penetración europea en la zona norte de Mesoamérica en el siglo Xvi. 
("los seguidores de Sigimar”), que se encuentran en fuentes medievales anteriores al siglo XI.

Otros topónimos en lenguas germánicas, más antiguos, terminados en el sufijo - heim, o sea hogar (o -ham -cham o -kam también en Inglaterra), se refieren no a un nombre propio, como en el anterior Sigimar, sino a una características geográfica, y son muy frecuentes en Alemania, como Nord-heim (hogar o caserío del norte), Weidenham (hogar o caserío de la pradera), Leadenham en Suffolk, Inglaterra. ${ }^{10}$ En el sur y occidente alemán son frecuentes los lugares relacionados directamente con Haus (casa), es decir, - bausen, con la variante -busen en el norte, y se relaciona con colonizaciones ordenadas por los señores territoriales, como Holzhausen en Bavaria, Kellinghusen en la frontera con Dinamarca. El equivalente en Mesoamérica serían topónimos terminados en -ichan (su hogar, su morada), como Coatlinchan. ${ }^{11}$

En un alemán antiguo, Althochdeutsch, de los siglos vIII a XI, se designaba "pequeño" con el término lützel (vinculado con la lengua germánica que dio origen al término inglés little). De ese lützel surgió Lützelberg (cerro pequeño) o castillo pequeño Lutzenburg, origen del actual nombre Luxemburgo. Pocos reconocerán, sin embargo el origen de ese topónimo en ese alemán antiguo. ${ }^{12}$ Así como el origen del nombre Luxemburgo es ya irreconocible, lo sería también el topónimo Zaragoza en España (que proviene de la

${ }^{10}$ Dyckerhoff, “Mexican Toponyms,” p. 247. Véase Dyckerhoff y Prem, Toponyme und Ethnonyme.

${ }_{11}$ Sustantivo chantli, morada, hogar, del que deriva el verbo chantia, nino. Vivir o morar en algún lugar, según Molina, Vocabulario, II, f. 19.

${ }^{12}$ Dyckerhoff, "Mexican Toponyms", p. 247. 
época del imperio romano, de César Augusto) o la ciudad francesa de Metz (derivado del nombre romano Mediomatricum) y muchos otros, como nos recuerda Guzmán Betancourt. ${ }^{13}$ Lo mismo les sucedería por ejemplo hoy a residentes de la Ciudad de México, a quienes sin duda les resulta totalmente enigmático el nombre de Churubusco o el del barrio de Mixcoac, siendo que el primer nombre originalmente se refería al importante Dios mexica Huitzilopochtli (Huitzilopochco) y el segundo remite a la emblemática deidad norteña de Mixcoatl. ${ }^{14}$ En esos casos el oscuro significado del nombre para los actuales residentes de la Ciudad de México se debe sobre todo al impacto que tuvo el español después de la conquista y a que el contexto social e histórico se ha transformado por completo. Así, bajo la importante influencia del español, una lengua muy distinta, a través del tiempo se ha perdido el significado original del nombre en náhuatl; ocurrieron cambios en la misma lengua y hubo un proceso de corrupción de los sonidos originales, tanto en el caso de /Huitzil a /Churu/, de /pochco/a /busco/ en México, como en el caso de Europa en los nombres de Zaragoza o Metz mencionados con anterioridad.

De los ejemplos anteriores de topónimos en distintas lenguas destacamos los procesos generalizados de transformación del contexto social e histórico, la corrupción de los sonidos y los cambios a lo largo del tiempo. En la Nueva España, por ejemplo, con el tiempo se transformaban las maneras de escribir los nombres indígenas e incluso la

13 Guzmán, De toponimia, p. 23.

14 La relación de la toponimia con el complejo ámbito religioso, estatal e institucional prehispánico será un tema que se abordará más adelante. 
misma fonología del español cambiaba. Podemos observar en la toponimia mencionada que también su misma morfología (o sea, sus variados sufijos o prefijos locativos) puede ser de interés para la reconstrucción del pasado, tanto al vincularse el nombre con determinada lengua como al proporcionarnos determinada temporalidad. Es decir, el análisis histórico arqueológico y documental, combinado con la lingüística, nos permite acercarnos a la pregunta: ¿qué cronología y qué migraciones sugieren locativos con determinadas características morfológicas? Intentemos ahora abordar esa pregunta analizando brevemente unos aspectos de la compleja situación multilinguística del México antiguo.

TOPÓNIMOS EN LENGUAS INDÍGENAS.

TRANSFORMACIONES EN EL TIEMPO, CALCOS Y SUFIJOS LOCATIVOS “CADUCOS” EN LA LENGUA NAHUA DEL SIGLO XVI

Afortunadamente podemos contar con listas de varios miles de topónimos indígenas de la época prehispánica que se conservaron en México después de la conquista. Gracias a las labores de los especialistas interesados en la geografía histórica o en la historia de los pueblos de indios, como Bernardo García Martínez y Gustavo Martínez Mendoza, Peter Gerhard y Dorothy Tanck, y de los etnohistoriadores, como Pedro Carrasco y muchos otros, que han reconstruido el pasado indígena con fuentes del siglo XvI, podemos observar un amplio universo de nombres en lengua indígena del periodo colonial. ${ }^{15}$ Sus estudios contienen también

${ }^{15}$ El universo de nombres que se analizará proviene, por lo tanto, de las listas de topónimos de las obras de los autores mencionados, añadiendo las de mis investigaciones sobre Cuauhnahuac y el norte de Guerrero. 
topónimos de poblados desaparecidos a lo largo del tiempo. En este caso debo mencionar que una hipótesis importante relacionada con mi investigación reciente sobre la zona llamada en el siglo xvi Coyxcatlalpan y sobre los chontales (del actual estado de Guerrero, cuya lengua desapareció en el siglo XVII) se refiere a la relevancia de una puntual expansión de grupos otomianos anterior a la época del imperio mexica, y por ello doy cierta importancia a la lengua matlatzinca. ${ }^{16}$

Es natural que en la amplia lista de topónimos en lenguas indoamericanas observemos claras concentraciones geográficas, por ejemplo, en el caso de nombres zapotecos, mayas o huastecos. En este último caso vemos en el noreste y la costa del Golfo de México múltiples nombres que inician con el prefijo locativo Tan o Tam (Tancoco, Tampico, Tamaulipas, Tamiahua, etc.) lo que se explica por la forma como se forman topónimos en la lengua huasteca, que es una lengua mayense; al encontrar los arqueólogos su cerámica por el Golfo hasta Texas, al ver un topónimo con su prefijo en lares tan lejanos como Tampa, Florida, sin duda podemos calificarlos como "los fenicios" de Mesoamérica. ${ }^{17}$

16 En el momento de la conquista, los hablantes de la variante nahua del río Balsas vivían en Coyxcatlalpan y se conocían como coyscas o cohuixcas. Su lengua se consideraba "menos pulida" que la del altiplano. TexeDA, "Informe", p. 249.

${ }^{17}$ No hay espacio para profundizar en el tema del transporte y del comercio fluvial y costero de los huastecos. Propongo que su expansión se refleja, en cierta manera, en la toponimia. Aunque faltan muchas evidencias materiales para fijar la cronología prehispánica y la expansión comercial de la cultura huasteca, G. Stresser-Péan explica, basado en evidencias arqueológicas (pipas, cerámica y esculturas características), que tuvieron relación durante el Clásico con las culturas del Mississippi mediante la navegación costera hacia Texas, llegando hasta Corpus Christi y la bahía de Matagorda. L. Ochoa Salas analiza sus vínculos también 
Aludiremos a ellos más abajo, en relación con la concentración geográfica de sus topónimos.

En la amplia lista de topónimos en lenguas indoamericanas, también podemos observar cómo resalta la preeminencia de nombres en lengua nahua que, sin duda, se relaciona con su prestigio y relevancia política. Este hecho complica un poco el panorama interpretativo, puesto que sabemos que no necesariamente eran los nombres que daban los nativos a determinado lugar. Se pueden apreciar algunos topónimos en esa lengua en el cuadro 1.

Como vimos arriba, se trata en muchos casos de lugares nombrados probablemente por los últimos que llegaron, y con frecuencia es una evidencia de nahuatización (o náhuatlización). ${ }^{18}$ Puede haber ocurrido en el siglo xv, durante el imperio mexica, en época anterior o, incluso, posterior, durante la conquista española, ya que los acompañantes de los conquistadores, indígenas del altiplano, nahuaparlantes, tuvieron un papel preponderante en la introducción y expansión de su lengua en zonas de pueblos distintos (por ejemplo en la zona ubicada al norte del altiplano y en la llamada Gran Chichimeca).

con los mayas. Stresser-Péan, Viaje a la Huasteca, pp. 233, 241, 255258; Ochoa Salas, Historia prehispánica de la Huasteca, p. 115. Propongo que el Golfo de México y el Caribe deben verse como un mar interior bien conectado por el comercio en las distintas épocas; sería "el Mediterráneo de América”, como decía A. de Humboldt.

${ }^{18}$ Seguimos la grafía normalizada de palabras en náhuatl de Wimmer, Gran Diccionario Nábuatl (GDN), www.gdn.unam.mx. Como nos referimos a topónimos registrados en documentos coloniales que no anotan longitud vocálica, no la señalo. Tales documentos, así como los textos en náhuatl de la misma época, utilizan la vocal /u/, que no existe en la lengua, y tampoco marcan la longitud vocálica. Si bien no la marco, estoy consciente de las ambigüedades que esto implica en algunos casos. 


\section{Cuadro 1 \\ EJEMPLOS DE TOPÓNIMOS EN LENGUA NAHUA}

\begin{tabular}{|c|c|c|}
\hline $\begin{array}{l}\text { Relacionados con } \\
\text { manantiales: ameyalli, } \\
\text { atzintli; } \\
\text { salinas, sal: iztatl; } \\
\text { arenales, arena: xalli; } \\
\text { espinales, espina: } \\
\text { buitztli; } \\
\text { aguas termales: } \\
\text { atotonilco; cerro: tepetl }\end{array}$ & $\begin{array}{l}\text { Relacionados con } \\
\text { frutos o vegetales } \\
\text { como algodón: } \\
\text { ichcatl; } \\
\text { pinos: ocotl; } \\
\text { paja, hierba: zacatl; } \\
\text { fruto de zapote: } \\
\text { tzapotl; fruto verde } \\
\text { xocotl }\end{array}$ & $\begin{array}{l}\text { Relacionados con la } \\
\text { fauna, como } \\
\text { grillo: chapolin; } \\
\text { cuervo: cacalotl; } \\
\text { serpiente: coatl; } \\
\text { venado: mazatl; } \\
\text { mariposa: papalotl; } \\
\text { jaguar: ocelotl }\end{array}$ \\
\hline Ameyalco & Ixcatepec & Chapultepec \\
\hline Atzinco & Ixcatlan & Chapulhuacan \\
\hline Atzitintla & Ixcateopan & Chapulapan \\
\hline Ixtapan & Ocotlan & Cacalotepec \\
\hline Ixtoyutla & Ocotepec & Cacalutan \\
\hline Ixtapaluca & Ocotitlan & Coatlan \\
\hline Xalpa & Zacatepec & Coatepec \\
\hline Xalapa & Zacatipan & Coatetelco \\
\hline Xaltepec & Zacatempan & Coatipac \\
\hline Huitzlan & Zacatelco & Mazatlan \\
\hline Huitzlingo & Zapotlan & Mazamitla \\
\hline Atotonilco & Zapotitlan & Mazatepec \\
\hline Tepexi & Zacatepec & Ozolotepec \\
\hline Tepepan & Xocotitlan & Ocelotlan \\
\hline Tepetitlan & Xocotla & Papalotla \\
\hline Tepetlan & Xoconusco & Papalocuatla \\
\hline
\end{tabular}

Se han observado en ese caso muchos calcos, es decir, el significado del topónimo nativo fue traducido literalmente a la nueva lengua hegemónica. Un ejemplo de Oaxaca sería el poblado de Huitlan (que remite a ihuitl, pluma menuda, 
en náhuatl), que se denomina hoy San Pedro Plumas; o Coatepec, topónimo nahua en lengua ocuilteca que se designa también como "lugar de serpiente". Así existen varios "lugar del juego de pelota", o sea, Tlaxco o Taxco en el altiplano, y ese significado se usó igualmente para nombrar, en tarasco, Querétaro. Otros calcos de la zona mixteca serían el pueblo llamado Yucucua/ Jiuace (cerro amarillo), que se nombró exactamente igual en lengua nahua, Cozauhtepec, y el caso del cerro del comal en mixteco, Yuku Tyiyo, se nombró en nahua Comaltepec, y así sucesivamente. ${ }^{19}$

La gran cantidad de topónimos en náhuatl con determinadas características en nuestra amplia lista a la vez nos permite observar la variante de la lengua nahua llamada "occidental", expresada sobre todo a lo largo de la costa del Pacífico. Esa variante no usa $/ \mathrm{tl} /$ - entre otras especificidades - y es característica del occidente de la actual República, probablemente desde épocas anteriores a la conquista. ${ }^{20}$ Por lo general fueron

19 También Tilantongo sería la traducción de Nuu tnoo, "lugar negro”, y Teozacualco la de Chiyo cahnu, "altar grande"; Anders, Jansen, Reyes "Introducción,” p. 37. Ante la convivencia multilingüística tan compleja en México, el tema de los calcos entre distintas lenguas (no sólo de topónimos) es en especial interesante. Los estudios de la relación entre el otomí y el náhuatl en el altiplano central, por ejemplo, aportan muchos elementos sociales, políticos y lingüísticos importantes para los interesados en el pasado. Véase Bartholomew, "Intercambio lingüístico" y WRIGHT, "Préstamos lingüísticos".

${ }^{20}$ Sobre el náhuatl occidental y el oriental véanse VALIÑas, "El náhuatl de la periferia"; CANGer y Dakin, "An Inconspicuous Basic Split in Náhuatl”; CANGer, "Los dialectos", DAKIn, "El náhuatl del norte y sur de Guerrero". En esta sección observaremos muy someramente la manera en que se forman topónimos en algunas lenguas amerindias para luego retomar el problema de la cronología histórica de la época prehispánica, para cuya resolución nos apoyaremos en dicha toponimia. Hay que 
las autoridades españolas quienes fijaron por escrito los nombres. Es interesante la distribución espacial de los nombres, y así vemos que en la documentación encontramos la toponimia $\sin / \mathrm{t} l$ / presente en lugares de la costa como Ixcatan en Nayarit, o Mazatan en Chiapas (no se usa el sufijo locativo tlan sino tan). Véanse más ejemplos en el cuadro 2.

\section{Cuadro 2}

EJEMPLOS DE DISTRIBUCIÓN ESPACIAL DE TOPÓNIMOS

\begin{tabular}{llll}
\hline $\begin{array}{l}\text { Topónimos en } \\
\text { variante nabua } \\
\text { occidental }\end{array}$ & $\begin{array}{l}\text { Ubicación a } \\
\text { lo largo del } \\
\text { Pacífico }\end{array}$ & $\begin{array}{l}\text { Topónimos } \\
\text { en lengua } \\
\text { buasteca }\end{array}$ & $\begin{array}{l}\text { Ubicación del } \\
\text { lado del Golfo }\end{array}$ \\
\hline $\begin{array}{l}\text { Amatan } \\
\text { Cacalotan }\end{array}$ & Chiapas & Tampamolon & San Luis Potosí \\
Cacalutan & Guadalajara & $\begin{array}{l}\text { Tancanhuite } \\
\text { Tamiahua }\end{array}$ & $\begin{array}{l}\text { San Luis Potosí } \\
\text { Huauchinango }\end{array}$ \\
Huecatan & Igualapa & Tampache & Huauchinango \\
Huehuetan & Chiapas & Tampasquin & San Luis Potosí \\
Huentitan & Guadalajara & Tampemoche & San Luis Potosí \\
Ixhuatan & Chiapas & Tamuín & San Luis Potosí \\
Ixcatan & Nayarit & Tamulte & Tabasco \\
Ixcatan & Guadalajara & Tancanhuitz & San Luis Potosí \\
Jocotan & Guadalajara & Tancoco & Huauchinango \\
Juchitan & Tehuantepec & Tancoyol & Cadereyta
\end{tabular}

advertir, sin embargo, que mucho de lo que sabemos de las lenguas indígenas proviene del análisis de aquellas que se llegaron a escribir durante el siglo XVI, además de los esfuerzos de numerosos lingüistas que entrevistan a hablantes de dichas lenguas en sus regiones, registran sus variantes regionales actuales y describen sus características. Son muy cuidadosos los especialistas en la cronología de los cambios, pues no es posible aún tener mucha precisión. Descartamos por controversiales las interpretaciones basadas en la glotocronología. 


\begin{tabular}{llll}
\hline $\begin{array}{l}\text { Topónimos en } \\
\text { variante nabua } \\
\text { occidental }\end{array}$ & $\begin{array}{l}\text { Ubicación a } \\
\text { lo largo del } \\
\text { Pacífico }\end{array}$ & $\begin{array}{l}\text { Topónimos } \\
\text { en lengua } \\
\text { buasteca }\end{array}$ & $\begin{array}{l}\text { Ubicación del } \\
\text { lado del Golfo }\end{array}$ \\
\hline Mazatan & Guadalajara & Tancuiche & Pánuco \\
Mazatan & Chiapas & Tanlajas & San Luis Potosí \\
Matatan & Sonora/Sinaloa & Tantima & Pánuco \\
Mecatan & Guadalajara & Tantoyuca & Pánuco \\
Mezquitan & Guadalajara & EJEMPLos EN & TABAsco \\
Ocotan & Durango & Amatitan & Tabasco \\
Tecpatan & Chiapas & Olcuatitan & Tabasco \\
Zapotan & Guadalajara & Tecoluta & Tabasco \\
\hline
\end{tabular}

Así, en contraposición con lo que expresamos arriba sobre los navegantes y comerciantes huastecos, podemos plantear que los nahuaparlantes ( $\sin / \mathrm{tl} /$ ) de la zona costera de Colima y Jalisco tendrían tal papel, para el océano Pacífico, quizá desde tiempos remotos. De tal manera se podría plantear que serían los grandes comerciantes los que a través de sus enclaves comerciales costeros lograron la expansión de su variante hasta Chiapas y Centroamérica.

Es útil saber cómo se forman los topónimos en distintas lenguas indoamericanas, pues hay una enorme variedad. Como explica Ángela Ochoa, el huasteco emplea varios recursos gramaticales para construir sus topónimos. En primer lugar utilizando el prefijo por excelencia formador de topónimos tan- (lugar, lugar de) y sus variantes tam- y temcomo lo observamos en la toponimia del cuadro $2 .{ }^{21}$ Otra

21 Otra manera, menos frecuente que la anterior, es anteponiendo la marca locativa "al" (en, hacia) a la palabra principal, como por ejemplo en Alaquich, o Almay o Alitze. Una tercera forma aún más simple y frecuente consiste en prescindir de los prefijos locativos, como en 
estructura morfológica totalmente distinta tienen los topónimos en matlatzinca y en ocuilteco. En este caso los marcadores locativos son be- y pi, noticia que tenemos gracias a que en la actualidad se han realizado estudios de estas lenguas, poco analizadas históricamente y que están en proceso de desaparición. Así, el matlatzinca, por ejemplo, se habla en un lugar de solo 2000 habitantes llamado San Francisco Oxotilpan y el ocuilteco se ha tratado de rescatar a partir de algunos hablantes que viven en San Juan Atzinco. ${ }^{22}$

Hemos insistido arriba en que los poblados suelen tener varios nombres, con frecuencia en lenguas distintas según los vaivenes históricos. Son numerosos los ejemplos de la zona norte del actual estado de Guerrero. Por ejemplo, informantes del siglo xvi del importante reino o señorío chontal llamado Tzicaputzalco decían que también se llamaba Pindexó. Esto remite a la presencia otomiana, probablemente relacionada con la expansión de Azcapotzalco, o sea, en época anterior al imperio tenochca (este poblado, vecino de Ixcateopan, se ha renombrado hoy como Ixcaputzalco, Guerrero). También sabemos que un barrio de otro reino chontal, cercano y de gran importancia local, Teloloapan, tenía el nombre de $\mathrm{Pi}-\mathrm{x}$-huahua. Es posible que esos antiguos nombres registrados en el siglo xvi remitan a nombres en matlatzinca, ya que en esa lengua de la familia otomangue, subgrupo otopame, los marcadores locativos son /be-/ y /pi/. ${ }^{23}$ Ese segundo

los lugares llamados Tutuche (cierta hormiga negra y pequeña) o Bojol (olote) o Jopoy (cierto árbol). OchOA, "Nombres de lugar en huasteco", pp. 135, 138.

22 Escalante, "Toponimia matlatzinca”, p. 165.

${ }^{23}$ Escalante, “Toponimia matlatzinca”, p. 165. Valiñas, "El matlatzinca y el ocuilteco". 
prefijo locativo lo encontramos, por ejemplo, en $P i$ - hewi que es el nombre de La Hoya, Pin- to- wháti, el nombre de México (en el cajoncito), Pí- suubí, el nombre para Temascaltepec; Pi-tetiri el de Valle de Bravo. En cambio, el prefijo /be/ lo observamos en otro locativo en los ejemplos Be-hás'i-un-tó, "en el cerro arriba de la piedra”, que es el nombre matlatzinca para Amanalco (en ese caso no hay calco). También lo observamos en Bé-s'i "lugar de encima", Albarranes. También hay muchas otras maneras de formar nombres (con artículos, con posesivos, tercera persona del plural, etc); por ejemplo, im-bo- máani (art. sing. negracasa), "Casa negra”, nombre de la ciudad de Toluca.

Una lengua que derivó del matlatzinca - quizá muy tardíamente, como propone el lingüista Leopoldo Valiñas - es el ocuilteco. ${ }^{24}$ Las lenguas matlatzinca, ocuilteco, como también el mazahua y el otomí se encuentran desde el siglo Xvi sobre todo en torno al Nevado de Toluca y al norte y occidente del altiplano central. Los ocuiltecos ubicados al sur usan también los prefijos "p" y "b" para formar topónimos, como Pun- du-jnáti (México). De la misma manera, para nombrar a San Juan Atzingo se dice Pun-bil, Ocuilan se dice We-baa (W), o Be-waa, o Ba-waá. La variedad de propuestas para un solo lugar proviene del problema de que ya hay muy pocos hablantes de ocuilteco y distintos autores han registrado, según su informante, distintos topónimos para un mismo lugar. ${ }^{25}$

De manera similar a los patrones de formación de topónimos en huasteco, matlatzinca y ocuilteco, que hemos

24 Valiñas, "El matlatzinca y el ocuilteco".
${ }^{25}$ Muntzel, "Topónimos ocuiltecos”. 
mencionado, es evidente que para la lengua nahua también hay ciertos patrones: han sido muy frecuentes ciertos sufijos locativos para nombrar lugares, como se observa en los topónimos en lengua nahua en los cuadros 1 y 2 (nombres en variante occidental). Es evidente la fundamental riqueza de nombres terminados en -c,-co,-pan,-can,-lan,-tlan, ti-tlan o-tan. Esos sufijos son tan comunes o, como dirían los lingüistas, "productivos” en esta lengua, que incluso hasta la fecha se pueden encontrar en nombres de lugar, como Cruztitlán (Puebla, siglo XviıI) o Hidalgotitlán (siglo xx), para sólo mencionar dos ejemplos.

Para la zona de Huexotzingo y Cholula, Ursula Dyckerhoff analizó los patrones de formación de topónimos, tanto los que surgen de manera descriptiva de accidentes geográficos como los derivados de hechos históricos y grupos étnicos. Menciona los sufijos anteriores, tan productivos ( $c$, co, lan, tlan etc.), y en cambio encuentra que ya no se usaba para nombrar lugares el sufijo - man. Se trata por lo tanto de una forma muy antigua de nombrar lugares, que ya no se empleaba en el siglo xvi. En la actual zona de Atlixco-Izúcar únicamente un solo nombre, el de Chalma, poblado que se encuentra cerca de Huaquechula, pervivía en el siglo XVI con ese sufijo. El hecho de que en la zona amplia del norte del actual estado de Guerrero haya yo encontrado varios topónimos (Chalman, Ticuman, Toliman, Oztuman) con este misterioso sufijo locativo antiguo, -man, me motivó a buscar más nombres con esas características. Se trata de un sufijo locativo al parecer ya obsoleto en los siglos XV y XVI. Veremos eso en la siguiente sección de este estudio, en la que nos acercaremos a las transformaciones de algunos nombres de lugar en náhuatl a lo largo del tiempo. 
Pero antes de pasar a ese tema de los nombres de misterioso significado, resumamos brevemente el resultado de lo antes dicho y relacionémoslo con ese problema. Como vimos, el origen de muchos topónimos puede comprenderse porque son: 1) descriptivos de características orográficas, hidrológicas, botánicas o zoológicas, y se forman con marcas locativas de manera específica según cada lengua. También pueden comprenderse porque: 2) se trata de las mismas descripciones, pero en otro idioma. En ese caso vemos que son calcos; 3) Igualmente podemos explicarnos su origen, como hemos dicho, gracias a que los nombres de lugar son resultado de migraciones o colonizaciones, como la mencionada Valladolid en Yucatán o el pueblo de Tlatelolco en la ciénaga del río Lerma en Toluca, o denotan la presencia de un grupo, por ejemplo, en Mesoamérica los mexicapan en distintas zonas. Pero hay otros topónimos de origen más oscuro: que 4) pueden referirse a instituciones del pasado; en el caso del México antiguo, a juegos de pelota, templos dedicados a ciertas deidades, edificios relacionados con determinados cargos políticos cuyo significado o relevancia no se conservó explícitamente. En el caso mesoamericano la explicación de su desaparición se relaciona con la conquista, la cristianización, el profundo impacto de la lengua española y el hecho de que los europeos relacionaran esos nombres con resabios idolátricos, peligrosos, con rituales y prácticas políticas “heréticas”. Aunado a eso, al expresar ideas religiosas o míticas castigadas de manera violenta, su significado original cambió o se perdió con el paso del tiempo. Veamos unos en el siguiente apartado. 
TOPÓNIMOS DE ORIGEN OSCURO, COMO CHALMA, OZTUMAN Y OTROS CON EL SUFIJO -MAN

Si bien arriba mencionamos que el proceso de corrupción de los nombres de lugares ocasiona en todas partes del mundo que el original significado de muchos topónimos sea irreconocible, ahora nos referiremos a otros nombres en lengua nahua de compleja comprensión, cuya estructura gramatical, o sea su morfología, es muy antigua y por ello irreconocible, incluso en la época mexica del siglo xvi. Veamos, por ejemplo, el testimonio de un informante de 1581. Cuando en ese año el alcalde mayor de Taxco levantaba una encuesta sobre la geografía e historia del lugar y preguntaba a un indígena "principal" local - probablemente bilingüe de lengua chontal y mexicano - los significados de los nombres de las distintas estancias, éste fácilmente las explicaba traduciendo los topónimos literalmente: Mazaixtlahuacan, valle donde se encontró un venado (de mazatl - venado e ixtlabuacan - valle), y de similar manera para Teticpac, Nochtepec, etc. Pero para el nombre de la estancia Chalman el informante decía al alcalde mayor que "era nombre antiguo de los indios, como quien llama a Pedro o Juan”. Es decir, para él era ya imposible descifrar o explicar el origen del topónimo y lo comparaba con los nombres de pila cristianos comunes como Juan o Pedro, incuestionados en la cultura cristiana por formar parte del bagaje cultural, religioso, interiorizado. Chalman le parecía tan común y anclado en su cultura como los antiguos nombres bíblicos cristianos de Pedro y Juan para un europeo del siglo xvi. ${ }^{26}$

${ }^{26}$ Relación de Minas de Taxco, p. 120. 
¿Pero a qué alude ese nombre? Para intentar descifrar ese topónimo común, interiorizado y normal en el siglo XVI, procedí a buscar otros con esa estructura gramatical. Resultó que en las listas de miles de topónimos del siglo xvi al XviII pocos tenían la antigua morfología que usa el sufijo - man y ésos se trataron de ubicar en la geografía mesoamericana. Además, resulta el nombre del verbo mani, estar, estar colocado o extendido.

Como se observa en el cuadro 3 y en el mapa 1, los lugares con esa terminación abundan en la zona del Pacífico y Pacífico norte, o sea, al sur de la región relacionada con el norteño centro de diferenciación de las lenguas de la familia yutoazteca en Durango y Sonora. Estarían esos lugares limitando al sur con los hablantes de las lenguas huichol y yaqui, pertenecientes a esa misma familia. Esto plantearía una temprana expansión por el sur de Jalisco y hacia Michoacán, donde se fundaron lugares como Alima, Colima, Cuacoman, Tecoman, Tetlama, Toliman, Zumpalmani. Además, podrían proponerse también posibles vínculos con poblados más sureños con esa antigua designación -man, pues Oztuman, al noroeste del actual estado de Guerrero, y Tetlaman, en Morelos (el poblado más cercano a la importante ciudad del periodo Epiclásico de Xochicalco), se relacionaron a lo largo de la historia a través de la Tierra Caliente de Michoacán y la cuenca del río Tepalcatepec con la cultura de Occidente. ${ }^{27}$ En la cuenca de ese río también hay sitios con este antiguo sufijo locativo.

27 Hacia los siglos vir y viII de nuestra era, la obsidiana que llegaba a Xochicalco provenía en gran medida de Michoacán, como muestran los estudios de Hirth et al., Archeaological Research, vol. 1, pp. 182, 202-208. 
Otros lugares terminados en -man claramente se ubican en el altiplano central, lo que podría indicar, desde mi punto de vista, que debe haber habido residentes que habían llegado en épocas remotas (quizá por los siglos del Clásico de Teotihuacan) a tales asentamientos muy antiguos. ${ }^{28}$

${ }^{28}$ En la dialectología de la lengua nahua en términos generales se ha reconocido una ruptura antigua que divide los dialectos en dos grupos, un grupo oriental (Sierra de Puebla, Huasteca, Guerrero central, Istmo, pipil) y otro grupo occidental. En esa escisión se aprecian varios rasgos, entre ellos en un fonema /i/ del proto-yutonawa, que en el grupo oriental resulta en $i$, y en los dialectos del grupo occidental en $e$. (Por ejemplo, moler tesi, masa textli, maíz sentli, uña istetl, estómago ibtetl en los occidentales, y en los orientales tisi, tixti, sinti, istit, ihti.) CANGER y DAKIN, "An Inconspicuous Basic Split in Náhuatl”. En un trabajo reciente Canger menciona que, después de esa escisión, ella ha encontrado sólo dos claras innovaciones, que son la introducción del -tin plural y el aumento /o/ en pasado de verbos, que no se conoce en la Huasteca, Sierra de Puebla, Istmo y pipil. A partir de ello postula que en los siglos Xv y Xvi se desarrolló un "náhuatl urbano" que creó formas nuevas. CANGER, "El nauatl urbano”. Acá se propone - a partir de la antigüedad de ciertos topónimosque la etnohistoria podría explicar un desarrollo históricamente más lento y la presencia de contactos, sobre todo comerciales, de larga duración entre lugares alejados, de norte a sur y de sur a norte, como aquellos ubicados en ciertas rutas. Esa postura se sostiene en Brígida von Mentz, "Nahuatización, multilingüismo y toponimia", ponencia presentada en el Congreso del Taller de Amigos de la Lengua Yutoazteca, celebrado en Cholula, Puebla, 2012. Su relativo aislamiento como variante antigua sucedió durante el Epiclásico. Después, durante el Posclásico temprano, otros grupos nahuaparlantes, también de mucho prestigio (relacionados con Tula, Texcoco, Cholula, etc.), se expandieron desde el altiplano. Entre las "islas de habla arcaica" estarían - entre otras - la Huasteca y el Guerrero de habla náhuatl cohuixca (de Coyscatlalpan) del siglo xvi. Claro está que convivieron en algunos sitios durante el Posclásico con otras lenguas y otras variantes del náhuatl, relacionadas con el imperio tenochca. Para observar los distintos enclaves de náhuatl en Guerrero es muy importante considerar ciertos estudios, como los de ValiÑas, "El náhuatl de la periferia", CANGER, "Los dialectos" y DAKIN, "Algunos 
Se trata de pueblos nahuaparlantes que usaban la terminación-man para designar lugares. Esos hablantes del náhuatl arcaico $-\mathrm{y}$ de gran prestigio - deben haber dado nombre a los lugares en el altiplano central, como Acolman, Tecama, Tolman, Ticuman y, más al sur, al cerro de Tetlaman, al lugar homónimo, cercano a la Villa de Guadalupe (Tetlaman), así como a los Tuliman o Toliman en el sur de Jalisco y numerosos, sobre todo, en las inmediaciones de Teotihuacan. Estos últimos topónimos remiten a tolin, juncia (con la que se tejen los petates), y al profundo significado del concepto del lugar del tular, que es una metáfora clave en la iconografía mesoamericana y en las pictografías, aludiendo a Tollan, el lugar de las artes, la urbe, la sede del poder, donde están los grandes templos y los hermosos palacios de los señores con esteras (petates), chalchihuites y tronos: los icpalli o asientos de poder. ${ }^{29}$

\section{Cuadro 3}

TOPÓNIMOS TERMINADOS EN - MAN

\begin{tabular}{llll}
\hline Nombre & Ubicación & Nombre & Ubicación \\
\hline Acalmani & $\begin{array}{l}\text { Huauchinango, } \\
\text { Puebla. }\end{array}$ & Tecamama & Igualapa, Gro./Oax. \\
Acatlimani & $\begin{array}{l}\text { Tlalcozauhtitlan, } \\
\text { Guerrero. }\end{array}$ & Tecama & $\begin{array}{l}\text { Ecatepec, Estado de } \\
\text { México. }\end{array}$ \\
& $\begin{array}{l}\text { cerca Teotihuacan, } \\
\text { Acolman }\end{array}$ & Tecoman & Colima
\end{tabular}

documentos nahuas", “Observación y percepción”, "El náhuatl del norte y sur de Guerrero."

29 Ejemplos de tal iconografía en distintos códices en Van Doesburg, Códices, pp. 30-31. Sin duda los lugares que remiten a esa metáfora ameritan más estudios y sobre todo investigaciones arqueológicas. 


\begin{tabular}{|c|c|c|c|}
\hline Nombre & Ubicación & Nombre & Ubicación \\
\hline Alima & Colima, Col. & Ticuman & Tacuba, México. \\
\hline Atzama & Tlaxcala, Tlax. & Ticoman & Yautepec, Mor. \\
\hline Chalma & $\begin{array}{l}\text { Zimapán, Tula } \\
\text { Hgo. }\end{array}$ & Tepeoxuma & Izúcar, Pue. \\
\hline Chalma & Meztitlan, Hgo. & Tetlaman & Tancítaro, Mich \\
\hline Chalma & $\begin{array}{l}\text { Amecameca, } \\
\text { Estado de México. }\end{array}$ & Tetlaman & $\begin{array}{l}\text { nte Villa Guadalupe, } \\
\text { México. }\end{array}$ \\
\hline Chalma & Izúcar, Puebla. & Tetlaman & Ixtapalapa, México. \\
\hline Chalma & Tehuacan, Puebla. & Tetlaman & Sitio Xochicalco, Mor. \\
\hline Chalma & Ocuilian, México. & Tiuma & Honduras \\
\hline Chalma & Chietla, Puebla. & Tlalaman & Chalco, Méx. \\
\hline Chalma & $\begin{array}{l}\text { Tlachco, } \\
\text { Guerrero. }\end{array}$ & Tlapuma & Tomatlan, Jal./Col. \\
\hline Chicolmani & Guerrero. & Tletlama & Tamazunchal S.L.P. \\
\hline Chinaminamina & Cozal, Guatemala & Toliman & Copala, Jal./Col. \\
\hline Chocaman & $\begin{array}{l}\text { Córdoba, } \\
\text { Veracruz. }\end{array}$ & Toliman & Zacatula, Mich./Gro. \\
\hline Coacoman & Motines, Mich. & Toliman & Sierra Gorda, Qro. \\
\hline Colima & Colima, Colima. & Tuliman & Huitzuco, Guerrero. \\
\hline Ichanosuma & $\begin{array}{l}\text { Esquinta, } \\
\text { Guatemala }\end{array}$ & Toliman & Atitlan, Guatemala \\
\hline Jicarimani & Honduras & Tolman & $\begin{array}{l}\text { Teotihuacan, Estado de } \\
\text { México. }\end{array}$ \\
\hline Jitlaman & $\begin{array}{l}\text { Cozcatlán/ } \\
\text { Tehuacan, Puebla. }\end{array}$ & Xiquiniman & Centicpac, Nayarit. \\
\hline Lejamani & Honduras & Zelama & Verapaz, Guatemala \\
\hline Oztuman & Teloloapan Gro. & Zuchitlama & Coatzacolaco, Ver./Tab. \\
\hline Xiquimani & Honduras & Zumpalmani & Colima, Colima. \\
\hline
\end{tabular}


También son muy numerosos los nombres de lugar Chalma. Existe con tal denominación el antiguo y famoso santuario al sureste de Toluca (Chalma, "Chalmita", municipio de Ocuilan), pero igualmente hay un Chalma en la zona de Amecameca, así como otro en Izúcar (todos cercanos a las estribaciones del Popocatépetl) y también en Chietla, Tehuacán y al sur de Taxco, no lejos de Iguala.

En Tacuba encontramos el topónimo Ticuman y también en Yautepec, en el camino de expansión teotihuacana descrito con frecuencia por los arqueólogos de la región lacustre hacia el río Mezcala Balsas (pues en Yautepec hay un sitio teotihuacano). Es homónimo del poblado en el lejano Colima. En esa misma ruta en Guerrero, en la zona que se llamó Coyxcatlalpan, estarían también otros lugares con nombres nahuas antiguos, como Toliman en Huitzuco y más al sur, en Tlalcozauhtitlan, Tolimani. Finalmente, hacia el este, encontramos los topónimos más alejados del centro de México con la terminación -man en la zona de Tehuacán y Teotitlán del Camino, en la ruta hacia el Golfo, en Xitlaman (Jitlaman), cuya población hasta la fecha es nahuahablante, y en Veracruz en Chocaman, cerca de Córdoba. La existencia de topónimos en -man en Centroamérica (Jicarimani, Zelama, Chinaminaman, etc.) confirmaría la hipótesis de la importancia de la presencia nahua en esos lares en el Clásico, probablemente relacionada con el comercio. ${ }^{30}$ (Véanse algunos ejemplos en el mapa 1.)

\footnotetext{
30 Agradezco a K. Dakin haberme proporcionado los topónimos en -mani que aparecen en documentos de Honduras. Otros lugares en Centroamérica se mencionan en García Martínez y Martínez Mendoza, Señoríos, pp. 1414, 1504, 2210, 3514, 3610, y provienen de un documento de 1684 del Archivo General de Indias en Sevilla.
} 


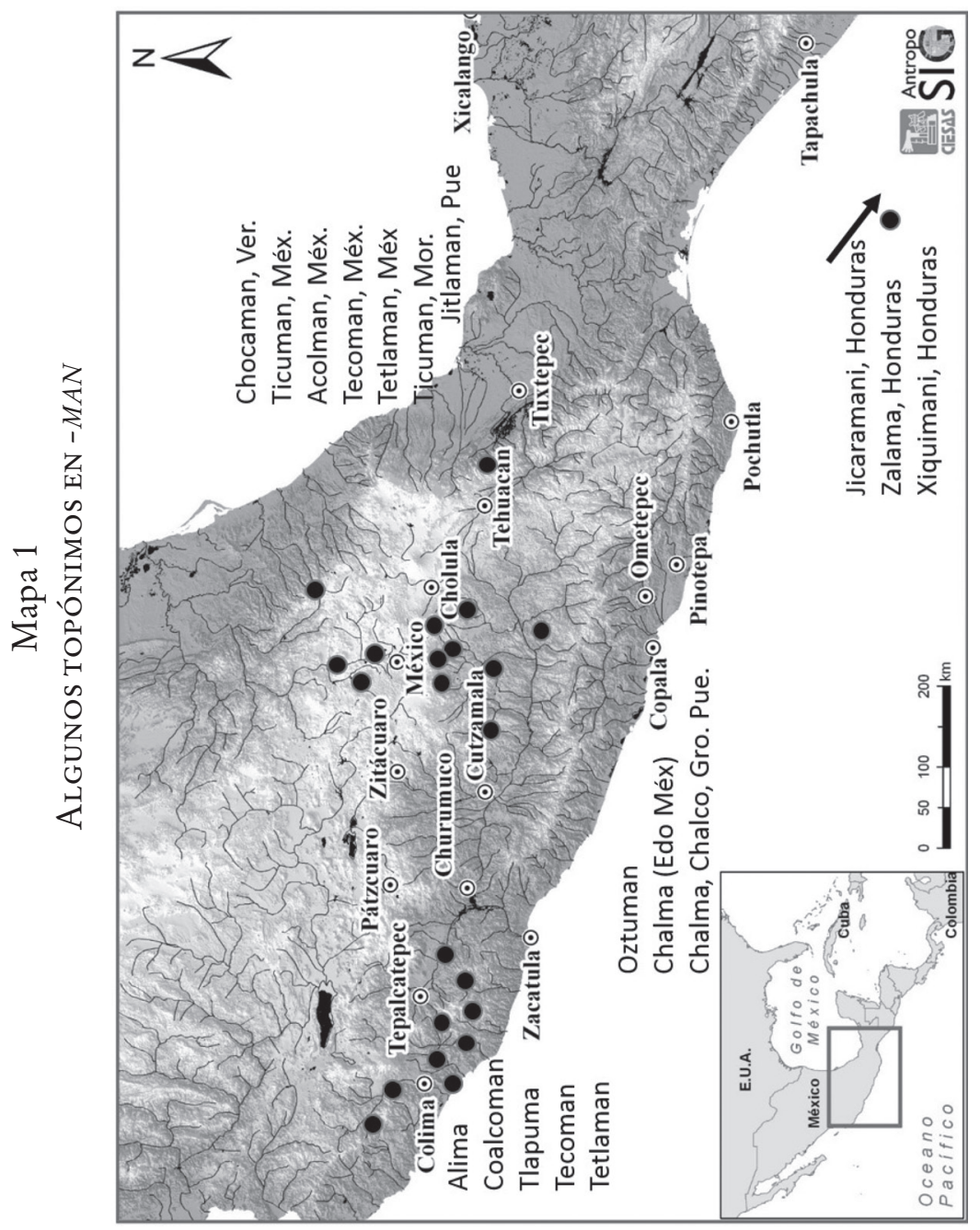


Propongo que hay varias vetas que deben seguirse explorando a partir de dos hipótesis: según la primera debería comprobarse con estudios arqueológicos, históricos y lingüísticos si tales rutas señaladas por esos nombres en un nahua arcaico pueden relacionarse con los mercaderes y el comercio a larga distancia desde la época del Clásico (100 a.C.-650 d.C.). Serían contactos relativamente permanentes, que quizá fomentarían el comercio a larga distancia (de norte a sur y de sur a norte), el cual se pudo haber mantenido por siglos.

En esa época de esplendor de Teotihuacan, la ruta hacia Tuxtepec y el sur del Golfo de México, se propone, podría haber pasado por Chalma (Amecameca) y Tepeoxuman en Izúcar hacia Tehuacán, luego hacia Xitlaman (Jitlaman) hacia Tuxtepec. Hasta la fecha existen importantes enclaves de habla nahua - con distintas variantes - en esa zona de Xitlaman, Coyomeapa, San Juan Cuautla. ${ }^{31}$ Igualmente se propone una ruta al Pacífico bajando por Valle de Bravo (el antiguo Temascaltepec o, en matlatzinca $P i$-tetiri) hacia el importante lugar de Oztuma, para llegar a las costas del Pacífico (Toliman, Zacatula, Petatlan, Soledad de Maciel), donde se podían obtener las codiciadas conchas marinas. ${ }^{32}$

31 Sepúlveda, Los lienzos de San Juan Cuaubtla. De la misma forma los municipios vecinos oaxaqueños donde predomina la lengua mazateca cuentan con algunos enclaves de población de habla nahua. Se trata precisamente del antiguo paso desde Tehuacan y Teotitlan del Camino hacia Tuxtepec y la costa del Golfo.

32 El nombre matlatzinca de Valle de Bravo, o "Temascaltepec de los indios" en el periodo virreinal, lo proporciona Escalante, "Toponimia matlatzinca”, pp. 163-166. Sobre la arqueología de esa costa véase MANZANILLA LóPEZ, La región arqueológica. 
La segunda hipótesis plantearía que el comercio antiguo, de la época del Clásico arqueológico, estaba relacionado - precisamente partiendo de las mencionadas rutas - con el intercambio de sal y por lo tanto con la deidad femenina de las salinas y el mar. Se propone que deberían relacionarse esos temas con la mencionada toponimia antigua. Recuérdese que eran famosas por sus salinas Oztuma, Tehuacán y Tehuantepec, localidades ubicadas en las rutas arriba mencionadas. Así, la fundación de lugares en lengua nahua arcaica podría relacionarse con el movimiento de mercaderes a las costas y sus contactos, colonizaciones puntuales e intercambios a lo largo del tiempo. Como demuestra el arqueólogo Rubén Manzanilla López, con los vestigios arqueológicos del Pacífico, que datan de la época de Teotihuacan (e incluso de épocas anteriores), abundan estatuillas de mujeres y alusiones a una deidad femenina. ${ }^{33}$ Esta importancia del vínculo entre la sal y el comercio desde épocas muy lejanas puede haberse conservado a lo largo del tiempo y se confirmaría con la existencia del culto en época mexica a una deidad femenina, Chalmeca-cíhuatl; llama

33 Manzanilla López, La región arqueológica. Sería de gran interés, respecto a la toponimia del Pacífico profundizar en la importancia de las deidades femeninas y en los nombres que abarcan desde Autlan, Jalisco, hasta San Salvador. Por ejemplo, Cihuatlan, Jalisco; Cihuatlan, Colima; Cihualpan, Cihua y Cihuatanejo (Zacatula), Cihuatan, San Salvador. Dicha importancia femenina parece tener una profundidad histórica notable, y quizá vincule también Mesoamérica con las costas de Centro y Sudamérica. Para la época mexica los informantes de Sahagún mencionan que la diosa de los salineros y del agua salobre era Huixtocíhuatl, hermana de los tlaloque. En esa época el señorío otomiano de Ocuilan, cercano al lugar de peregrinación Chalma, era el que concentraba los tributos de sal de toda la zona de salinas, desde Tejupilco hasta Ixtapan de la Sal, como se observa en la Matrícula de tributos, lámina XIV. 
la atención el nombre de esta "señora de la gente de Chalma”. Esta se menciona como diosa de los mercaderes del barrio de Ahuachtlan en Tenochtitlan. Proponemos así que también sería factible que los numerosos lugares llamados Chalma que observamos en el cuadro 3 estuviesen articulados a un antiguo comercio y al culto a esa diosa de la sal y la blancura. ${ }^{34}$

De esta forma, gracias al análisis toponímico podríamos arrojar algo de luz sobre la cronología prehispánica y conocer o intuir movimientos de los pueblos de habla nahua con presencia mucho anterior a los mexica; pueblos cuya variante nombraba los lugares con el sufijo - man y que pueden haberse expandido en época de Teotihuacan. Sobre la importancia de la llegada de hablantes de nahua a la gran ciudad teotihuacana nos dice la lingüista Karen Dakin:

Probablemente desde cerca de 400 DC habían llegado a la zona central los primeros nahuas, hablantes de una variante "oriental” y después se fueron dispersando [...] algunos documentos muestran las características del dialecto del náhuatl oriental y que tiene una presencia histórica en el sur de Mesoamérica desde periodos más antiguos. ${ }^{35}$

${ }^{34}$ Esta hipótesis la menciona Van Zantwijk al hablar de los mercaderes en Tenochtitlan y sus lugares de culto en época de los mexica. ZANTwiJk, The Aztec Arrangement, p. 139. No compartimos su hipótesis de que la gente de Chalma pueda identificarse con la gente de las chinampas al sur de la cuenca de México sino, como hemos expresado, consideramos que los lugares Chalma, como muchos otros con estructura gramatical semejante, pueden vincularse con pobladores de la época del Clásico arqueológico, hablantes de un antiguo náhuatl y que se relacionaban con el intercambio de sal y el comercio a distancia.

${ }^{35}$ Dakin, "Algunos documentos nahuas", pp. 248 y 265. 
Y en otro texto expresa la misma autora:

[...] si la asignación de un origen yutonahua a la palabra kakawa-tl es correcta, entonces la fecha de la copa (maya) del siglo $\mathrm{v}$ implica que los nahuas pueden haber sido una de las poblaciones de Teotihuacan en el periodo Clásico; significa que su lengua tenía suficiente prestigio, de tal forma que la palabra se presentara en las lenguas mayenses y otras y que apareciera escrita $[\ldots] .{ }^{36}$

Propondría como hipótesis que probablemente hayan quedado hablantes de esa variedad "oriental" o "arcaica" en ciertas zonas como la Huasteca y el centro de Guerrero, y que fueron parcialmente desvinculados del altiplano en el Epiclásico y Posclásico. Quedaron escindidos en los siglos VII-IX por una especie de cuña, al penetrar los pueblos que se establecieron en Xochicalco o en Cacaxtla, que aislaron a los nahuaparlantes del Balsas del altiplano.

Posteriormente nuevos grupos llegaron a Tula y a Teotenango y en esa nueva época, entre los años 1000 y 1200, de gran comercio y vínculos lejanos con el mundo maya y con el norteño, nuevas culturas penetraron como cuchillas que continuaron aislando a los grupos nahuaparlantes de la Huasteca de aquellos de Coyxcatlalpan. Así quedó dividida la misma variante antigua oriental en la zona del Balsas (hoy Guerrero) y la Huasteca. Además, en otros lugares, los colonos nahuaparlantes - quizá comerciantes - desarrollaron más su propia variante, muchas veces bajo la influencia de otras lenguas indoamericanas circundantes, por ejemplo en

${ }^{36}$ Dakin, “Observación y percepción”, p. 152. 
la costa del Golfo, el Istmo, al igual que en Pochutla (Oaxaca) en el Pacífico y en las lejanas Zelama, Lejamani o Jicaramani en Honduras. ${ }^{37}$ Sin duda en Pochutla, Oaxaca, influyó mucho la expansión y el vigor del reino mixteco del señor Ocho Venado Garra de Jaguar, que dejó aislada dicha plaza comercial en el siglo XI, y con menos contacto con nahuaparlantes, hasta la llegada de los españoles. De esta forma se explicaría, para el centro y norte del actual estado de Guerrero, que la variante nahua antigua quedara aislada y que fuese la misma que quedó marginada hacia el oriente en la Huasteca.

Hay que tener presente, además, que ocurrieron muchísimas migraciones y movimientos de población en el transcurso del tiempo y que pueden reflejarse en una toponimia modificada o desaparecida. Así sabemos por la historia colonial que muchos indígenas de reinos cercanos a las minas de plata, como los coyxca, huyeron al sur y a las montañas de Tixtla sobre todo a fines del siglo xvi, y en cambio reinmigraron al norte del río Balsas en el siglo xviII, donde encontraron la posibilidad de arrendar tierras de los grandes latifundios pertenecientes a la oligarquía minera, como la familia Borda, por ejemplo.

${ }^{37}$ Véase el análisis de un documento en lengua nahua de Jicaramani, cerca de Tegucigalpa, Honduras, en DAKIN, "Algunos documentos nahuas," pp. 260 y ss. La presencia posterior de nahuaparlantes en la ruta hacia Tuxtepec, en la región de Tehuacán y Teotitlán del Camino, se ha relacionado, por la Historia tolteca-chichimeca, con la expansión nonohualca. Véase Sepúlveda, Los Lienzos de San Juan Cuaubtla, pp. 52-61. 


\section{ALGUNOS NOMBRES DE LA ÉPOCA MEXICA Y SU DISTRIBUCIÓN GEOGRÁFICA}

Si hemos planteado en el apartado anterior la hipótesis de que los nombres terminados en - man podrían remontarse a la época arqueológica del Clásico (200-650 d.C.), como se vio en el mapa 1, para terminar quisiera plantear una hipótesis relacionada con la toponimia que, a mi juicio, advierte la presencia imperial de la Triple Alianza (1460-1519 d.C.) en ciertas zonas. Como se dijo arriba, el problema con la gran cantidad de topónimos en lengua nahua se debe a que fue la lengua de poder y prestigio durante todo el periodo colonial, y por tanto también se siguió difundiendo durante el siglo xvi a partir de la expansión imperial española. Ello complica el reconocimiento de la época en la que fue nombrado un lugar en lengua nahua, pues puede ser anterior o posterior a la conquista europea. ${ }^{38} \mathrm{Sin}$ embargo, como vimos al hablar de ciertos nombres de origen oscuro, existen algunos que se refieren al ámbito religioso, por lo que al desaparecer las instituciones prehispánicas (dedicadas a Huitzilopochtli o a Mixcoatl) dejaron de originarse nombres que se refieran a ellas. Por lo tanto, si en la toponimia de los

38 La cuestión de la escasa influencia lingüística del náhuatl en muchas zonas de Oaxaca, a pesar de la gran cantidad de toponimia en esa lengua, merece una discusión más amplia. Valiñas cita a Gumperz y Wilson (1971), quienes sugieren que el léxico puede servir como un emblema de identidad étnica. Esto le permite a Smith-Stark (1990), como dice Valiñas, "tener una vía más para explicar la baja presencia de préstamos en las distintas lenguas oaxaqueñas”. VALIÑas, "Historia lingüística: migraciones”, p. 148. 
siglos coloniales, o aún hoy, encontramos su rastro, sin duda se trata de un lugar antiguo, fundado en época prehispánica.

Antes de proceder a localizar algunos de esos topónimos mexica estatales y mostrarlos en el mapa 2, debemos ser conscientes de lo complejo que es reconocer nombres cuando se han transformado mucho. Ya vimos al inicio cómo en todas partes del mundo se llegan a deformar tanto los nombres de lugar que sus orígenes se desvanecen; recordemos, por ejemplo, que Zaragoza proviene de César Augusta, que Metz proviene de Mediomatricum, y así sucesivamente. Los cambios pueden ser muchísimos. Pero hay cierto patrón en las deformaciones, como vemos al analizar la manera en que se han transformado los nombres comunes en lengua náhuatl que usamos en México, por ejemplo, de buitzayotl (calabaza con espinas) a chayote $(t z>c h, t l>t e)$. Hay cierta lógica interna en la forma en que se fueron deformando los sonidos por distintos motivos, sobre todo por el contacto con hispanohablantes. En documentos anteriores a 1570, por ejemplo, vemos que muchos topónimos se castellanizaron simplemente siguiendo el sistema fonológico del español. Por ejemplo, si terminaban en -c, como Zacatepec, se anotaban Zacatepeque; Yautepec se volvió Yautepeque, y también se transformaron en /ca/, como en Cuernavaca; además, la /tll/ de algunos nombres terminó siendo / te/ o se simplificó a /t/ como Tlilantongo, en Tilantongo; los numerosos morfemas con /tz/ (buitztli, espina, etc.) se simplificaron en /ch/ como en la ya mencionada verdura buitzayotl en chayote. 


\section{Cuadro 4}

DISTINTAS FORMAS EN LAS QUE SE ESCRIBIERON ALGUNOS TOPÓNIMOS Y PROCESOS DE CORRUPCIÓN

\begin{tabular}{ll}
\hline Nombres & Ejemplos de la forma que toman en las fuentes, cambios \\
\hline Pochutla & Puchutla o $>\mathrm{u}$ \\
Cuauhtla & Huautla, Guautla c $>\mathrm{g}$ \\
Ahuatlan & Agoatlan hua $>$ goa \\
Huatulco & Guatulco hua $>$ gua \\
Huautla & Guautla hua $>$ gua \\
Cuauhnahuac & Cuerna-ba- ca hua $>$ ba \\
Ahuehuetlan & Abebetlan hue $>$ be \\
Cuauhtochco & Huatusco cua $>$ hua \\
Tegoantepec & Tehuantepec goa $>$ hua \\
Cuauh-tla & Huau-tla uauh $>$ ua \\
Cuauh-tla & Guau-tla uauh $>$ ua \\
Cuauhchinanco & Huachinanco/ Guachinanco Cuauh $>$ Hua Cuauh $>$ Gua \\
Coatinchan & Guatinchan coa $>$ gua \\
Coatepec & Goatepec coa $>$ goa \\
Coazacualco & Guazacualco coa $>$ goa \\
Xochicotlan & Sochicotlan /sho/ $>$ so, su, ju \\
Axocopan & Ajacuba xo $>$ ja \\
Axalpan & Ajalpan xa $>$ ja \\
\hline
\end{tabular}

FUENTE: Libro de las tasaciones (abarca de 1535 a 1570); CARRASCO, 1996; Gerhard, 1986.

Otros cambios también parecen ser relativamente sistemáticos. Vemos que el sonido /hue/ con frecuencia se escribió /gue/ y así Ahuehuepan terminó siendo Agueguepan; el mismo sonido también podía transformarse en /be/, de 
tal manera que encontramos Abebepan. Lo mismo sucedió con la /hua/, que pudo transformarse en /gua/ pero también en ocasiones en $/ \mathrm{ba} /$. La /c/ inicial podía palatalizarse y con frecuencia es /g/, de tal manera que Cuauhtla sería sinónimo de Guautla y de Huautla. Este nombre puede referirse al "lugar donde abunda el huautli (amaranto)", pero también "lugar donde abundan los cuaubtli (águilas); es decir, el término se presta a confusión por buautli- amaranto, el vegetal, cuaubtli-águila, por los distintos modos de fijar por escrito los nombres. Además, también complica la identificación de ese topónimo lo fácil que es confundir los derivados de cuabuitl- árbol, de aquéllos derivados de cuaubtli- águila). Aparte de esa triple complicación del nombre Guautla (amaranto, águila, árbol), considero que es fundamental observar la ubicación de esos nombres: cuando se trata de parajes estratégicos, ubicados en rutas de comercio y en la cima de montañas, opto por traducirlo como lugar de águilas. El concepto metafórico de cuaubtli como guerrero me parece central y en ese sentido es fundamental reconocer, para esos casos de ubicación estratégica, los topónimos Huautla, Guautla, Cuauhtla como sinónimos.

Desde mi punto de vista, tomando en cuenta la variedad en la escritura de sonidos como los arriba mencionados, se pueden distinguir topónimos relacionados con la institucionalidad mexica y con la expansión tenochca, a pesar de múltiples transformaciones. Esto se debe tanto a lo específico de su contenido como a su localización en determinados lugares geográficos. Me referiré específicamente a los topónimos Huautla-Cuauhtla, Tlacochcalco y Acapetlahuaya.

Como es bien sabido, en Tenochtitlan los cargos más importantes, además de los señores de linaje, los Tlatoque 
(tlatoani en singular) y el Cibuacoatl, fueron el señor Tlacatecatl Tecubtli (Teuctli) y el Tlacochcalcatl Tecubtli (Tenctli), consignados en códices como la Matrícula y el Mendocino y en la historiografía del siglo xvi. El último cargo nos interesa por ser el de capitán general, o sea, el máximo cargo militar, por lo que se trataría de los personajes que mayormente deberíamos encontrar a lo largo y ancho del imperio tenochca. Su presencia se hacía sentir sobre todo por su control de las armas en las localidades estratégicamente importantes. De hecho, la traducción del cargo se refiere al "señor de la casa de los dardos (flechas o lanzas)", es decir, señor del Tlacochcalli. Como he comprobado con detenimiento para los valles de Cuauhnahuac, este Tlacochcalcatl Tecutli (Teutli) tenía tierras de cargo y recibía renta de ellas. En los minuciosos censos que han llegado de esta zona de la época de 1540 en náhuatl y en grafía latina, observamos que las tierras de cargo contaban con un número de terrazgueros que entregaban directamente al general su renta y servicios.

Sabemos que muchas veces en tierras de cargo (como en las tierras del señor de linaje, que podían ser numerosas) se acomodaban muchos inmigrantes de otros lugares y se les daban parcelas muy pequeñas que esos campesinos pobres labraban, y a cambio entregaban textiles, maíz, huevos y demás tributos al señor. Esas tierras se denominaban Tlacochcalco y el Tlacochcalcatl Tecubtli era la instancia (como los demás grandes señores) que repartía las tierras para que no quedara palmo sin ocuparse y labrarse. Los que vivían en Tlacochcalco podían denominarse tlacochcalca (plural con saltillo, de tlacochcalcatl). De la misma manera se designaban los moradores y cultivadores de otras tierras de cargo 
o adscritas a templos u otras instituciones. ${ }^{39} \mathrm{~A}$ diferencia de los terrazgueros que podían provenir de distintas partes y ser de culturas y lenguas distintas, propongo que ciertos núcleos de colonización mexica claramente toman los topónimos alusivos como Mexicapan (existentes en Cuauhnahuac, en Teloloapan en zona chontal, en Epatlan, Izúcar, en Comayagua, Guatemala, entre otras) o se refieren directamente a los guerreros como “águilas”. Por ejemplo, entre varios palacios en Cuauhnahuac, uno se denomina Cuauhtecpan (y está situado al norte de Xochicalco, al occidente del Tecpan, relacionado con Panchimalco, actual Cuernavaca-Vergel.)

En la Matrícula de tributos también se escribe con claridad, con la imagen de una cabeza de águila, el topónimo

39 A partir de los censos en náhuatl de 1540 (Mentz, Cuaubnabuac, capítulos 3 y 4) se pudo comprobar que los terrazgueros de los nobles moraban en las tierras de cargo de altos funcionarios. Así, al hablarse de su lugar de origen, se usaban gentilicios como buitznahuaca o tlacochcalca. Estos gentilicios, que designan así a los campesinos que moran en esos lugares, no deben confundirse con los señores. Era muy distinto el capitán general, Tlacochcalcatl Tecubtli, a un tlacochcalcatl cualquiera; de la misma manera era muy distinto un Huitznahuácatl Tecuhtli a un terrazguero caracterizado como buitznabuácatl. Considero que muchas fuentes del siglo Xvi escritas por españoles o indígenas que reivindican el pasado mexica confunden como gentilicios a grupos de moradores de determinado lugar, pero que no conforman un pueblo de por sí. Tezozomoc, por ejemplo, habla de que Huitzilopochtli escogió su zumpantli y su juego de pelota "en el calpulli de los huitznahua”. Considero que eran los moradores de Huitznahuac o de Tlacochcalco, pero no se trata de una etnia. Los residentes de determinada parcialidad se denominaban así, sin que ello convirtiera a cada paraje habitado en el origen de una etnia o pueblo específico. En tierras de cargo o de templo podían habitar y trabajar gente de muy distinta cultura, lengua y origen. Existe también la posibilidad de pérdida de la /ch/ en topónimos de lugares estratégicos como Tlacotepec, como el de la sierra sur (cerca de Huautla) en Guerrero o en Toluca. 
Cuauhtla, ubicado en la importante ruta al pie del Popocatépetl hacia Chalcatzingo e Izúcar (y hacia el Golfo, como vimos arriba). Está relacionado, siguiendo el curso del río Cuautla, con el estratégico poblado de Huautla a lo alto de la serranía (como también la antigua fortificación de Cerro de Venado), precisamente en zona de frontera y de control del paso del río Amacuzac. ${ }^{40}$ Así podemos observar en el cuadro 5 la localización de nombres que aluden a numerosas sedes militares y residencias de "guerreros águila" (Cuaubtla), así como a tierras del capitán general (Tlacochcalco). De igual importancia militar que la presencia de un capitán Tlacochcalcatl Tecubtli era sin duda un arsenal o el lugar donde se preparaban las armas. Considero que el topónimo Acapetlahuaya o algunas variantes de ese nombre se refieren a tal lugar específico donde se acondicionaban las armas, pues el nombre se deriva de acatl caña y petlahua (nitla) bruñir, lucir. Es decir, se pulían las cañas para lanzas y flechas en ese arsenal, que precisamente encontramos en puntos tan estratégicos como Oztuma (Acapetlahuaya de los mexicanos, poblado junto a la fortificación mexica), así como en Huaquechollan en la frontera con Cholula y sus aliados y en el lejano Xoconusco en Chiapas.

40 Sobre la congregación de Santa Clara Cuauhtecpan, Mentz, Cuaubnabuac, p. 382. Es probable que en la zona de Texcoco el palacio o la guarnición de los guerreros se haya denominado con el locativo -ichan. No se trata de un sufijo locativo común y es posible que los topónimos Coatlinchan y Cuauhtinchan se refieran a cuarteles militares, verdaderas moradas de guerreros, y se utilizaba la metáfora de las serpientes y las águilas para militares, o quizá el primero, coatl, para funcionarios. Recuérdese el más importante, el cibuacoatl. El tema de las metáforas del poder amerita otro estudio. 


\section{Cuadro 5}

TOPÓNIMOS QUE ALUDEN A INSTITUCIONES MEXICAS

\section{MILITARES}

\begin{tabular}{|c|c|}
\hline Topónimo & Ubicación (aprox. 1519) \\
\hline Tlacochcalco & $\begin{array}{l}\text { Cuauhnahuac. Tierras del capitán, residen } \\
\text { colonos inmigrantes. }\end{array}$ \\
\hline Tlacochcalco & Tepoztlan, Cuauháhuac, \\
\hline Tlacochechac & Metztitlan. Guerra contra huastecos, entre otros. \\
\hline Tlacochaca & $\begin{array}{l}\text { Tonatico, Edo, de México. Guerra contra } \\
\text { matlatzincas y chontales. }\end{array}$ \\
\hline Tlacoxcalco & $\begin{array}{l}\text { Tehuacan, Coxcatlan, ruta al Golfo, hacia } \\
\text { Tuxtepec }\end{array}$ \\
\hline $\begin{array}{l}\text { Tlacochcalco } \\
\text { Tlacochcalco } \\
\text { Tlacochcalco } \\
\text { Tlacuscalco }\end{array}$ & $\begin{array}{l}\text { Tlaxcala (hay dos). } \\
\text { Huejotzingo (Matrícula de H). } \\
\text { Coatlinchan (Mapa de C). } \\
\text { Huehuetlan,Tepexi, límite con popolucas, Edo. } \\
\text { de Puebla. }\end{array}$ \\
\hline Tlacoach-ixtlahuaca & $\begin{array}{l}\text { Igualapa, ruta al mar. Imp. Pinol-tecpan, hoy } \\
\text { Pinotepa en la ruta costera. }\end{array}$ \\
\hline Acapetlahuacan & $\begin{array}{l}\text { Lugar para pulir lanzas. Atlixco, guerra contra } \\
\text { Cholula y otros. }\end{array}$ \\
\hline $\begin{array}{l}\text { Acapetagua } \\
\text { (Acapetlahuan) }\end{array}$ & $\begin{array}{l}\text { Lugar para pulir lanzas. Chiapas, guerras en } \\
\text { Xoconusco. }\end{array}$ \\
\hline Acapetlahuayan & $\begin{array}{l}\text { Lugar para pulir lanzas. Oztuma, guerras contra } \\
\text { tarascos. }\end{array}$ \\
\hline Cuauh-tecpan & $\begin{array}{l}\text { Cuauhnahuac, palacio al poniente (Sta. Clara en } \\
\text { el siglo xvi). }\end{array}$ \\
\hline 4 Cuauh-tlalpan & $\begin{array}{l}\text { Texcoco, Chalco, Ecatepec, Cuautitlan, } \\
\text { Cuauhtenco, Cuauhtepec. }\end{array}$ \\
\hline Huautla / Cuautla & Teotitlan del Camino, ruta a Tuxtepec. \\
\hline Huautla / Cuautla & $\begin{array}{l}\text { Sur de Chalco (hoy Cuautla, Morelos), ruta al } \\
\text { sur al Balsas. }\end{array}$ \\
\hline
\end{tabular}




\begin{tabular}{|c|c|}
\hline Topónimo & Ubicación (aprox. 1519) \\
\hline Huautla / Cuautla & $\begin{array}{l}\text { Montañas al sur del actual Morelos, paso del } \\
\text { Amacuzac al Balsas. }\end{array}$ \\
\hline Huautla / Cuautla & Yahualica, Huasteca, guerra contra huastecos. \\
\hline Huautla / Cuautla & $\begin{array}{l}\text { Tetela del Río, en la sierra, guerra contra yopis, } \\
\text { cerca de Tlacotepec. }\end{array}$ \\
\hline Huautla / Cuautla & Teposcolula, en la Mixteca Alta. \\
\hline Huautla / Cuautla & En Tehuacán, ruta al Golfo, hacia Tuxtepec. \\
\hline Huautla / Cuautla & En Atlixco, guerra contra Cholula y otros. \\
\hline Huautla / Cuautla & $\begin{array}{l}\text { Guadalajara, ¿frontera tarasca contra pueblos de } \\
\text { Colima? }\end{array}$ \\
\hline
\end{tabular}

Además, como hemos dicho, postulamos que generalmente son sinónimos los Cuauhtla, Huautla o Guautla, por la dificultad del sonido /w/ y por la diferente manera de fijarlo por escrito en la documentación. Si observamos la escritura pictográfica de esos lugares vemos en distintas fuentes que convergen y remiten a la presencia militar. En este caso propongo que aquellos lugares así llamados y ubicados en distintos puntos geográficos, como se observa en el cuadro 5, pueden referirse a tierras del capitán general mexica en esa zona o a guarniciones y presencia de guerreros águila en esos parajes estratégicos. ${ }^{41}$

41 Quizá esta forma de localizar algunos lugares estratégicos pueda apoyar a los estudiosos que hasta ahora se han basado únicamente en la mención de determinadas guarniciones en las fuentes mexicas y la historiografía del siglo xvi. Véanse, entre muchas otras obras, Códice Mendocino; Carrasco, Estructura; Smith y Berdan, The Postclassic Mesoamerican World. 


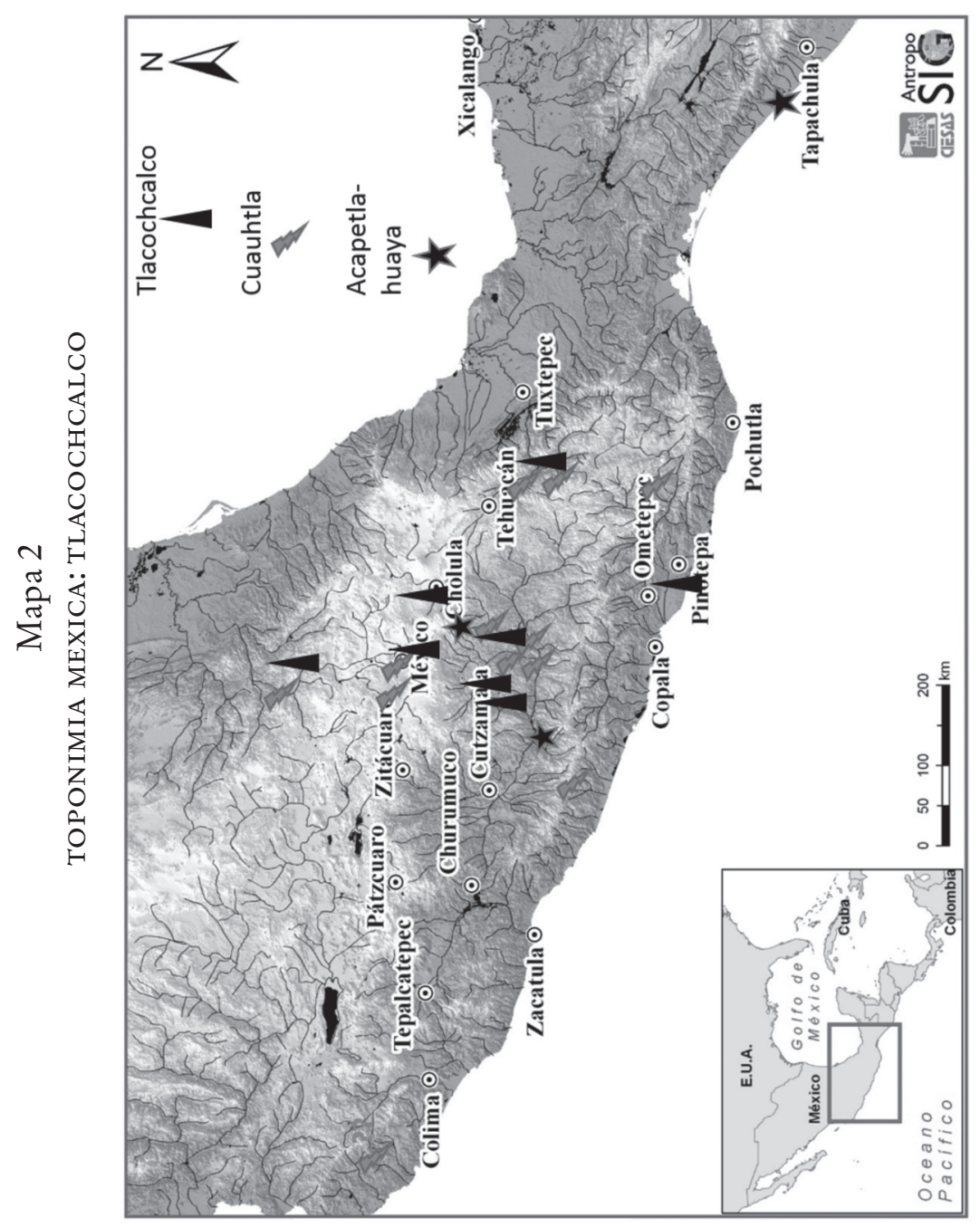


Así, la hipótesis relacionada con la toponimia mexica que proponemos estaría expresamente vinculada con la expansión de sus instituciones centrales militares en determinados puntos del imperio. La distribución geográfica de esa toponimia revelaría, por ejemplo, la existencia en determinados lugares de tierras del Tlacocbtecatl Tecubtli (y sus terrazgueros), y la toponimia también podría reflejar la existencia de palacios de guerreros, quizá fuertes militares, los Cuaubtecpan o los Cuaubtla diseminados de manera estratégica (véase el mapa 2). Nótese la importancia de ciertas rutas, que hemos caracterizado como muy antiguas, como la que conducía de Tehuacán y Teotitlán del Camino a Tuxtepec, donde existen varios Cuauhtla (hoy San Juan, municipio de Coyomeapan), cerca del antiguo poblado de Jitlaman (Xitlaman), como proponemos, de hablantes de nahua arcaico, y cerca también, más al sur, Huautla en la sierra mazateca, todos poblados ubicados en la sierra justo antes del descenso del camino a la rica plaza mercantil de Tochtepec. $^{42}$ Esta toponimia, además, está probablemente imbricada, de manera compleja, con muchas otras nociones religiosas, jurídicas y militares que ameritan muchos otros estudios detallados.

42 Sobre San Juan Cuauhtla, Puebla, sujeto hoy de Coyomeapa, y su historia véase Sepúlveda, Los lienzos de San Juan Cuaubtla, pp. 33, 41-45. Actualmente se hablan distintas variantes del nahua. Colindando al sur, en la sierra mazateca, se ubican Huautla de Jiménez y San Miguel Huautla. Se trataría precisamente de la antigua ruta a Tuxtepec, aquí propuesta, vía Tehuacan, o vía Teotitlan, siguiendo el cauce de los ríos. También el topónimo Coyomeapan (río de los coyotes) y el vínculo de los mercaderes y su dios principal el Coyotl inabual, en época mexica puede referirse a un muy antiguo culto al coyote al que no podemos sino aludir por falta de espacio. 
Es importante advertir que, en las traducciones populares de topónimos, se alude por lo general a una descripción geográfica o relacionada con la flora y fauna reconocible en los vocablos del topónimo. Existe, sin embargo, una contradicción entre esas traducciones literales populares y la documentación antigua, por ejemplo, si observamos las pictografías tempranas de Cuautla (hoy estado de Morelos) lejos de ser el lugar del "bosque" - como se traduce por lo general-, se dibuja con un águila, o sea, remite al cuaubtli, al águila o guerrero (véase la imagen). El estratégico paso hacia el sur de Amecameca-Cuauhtla-Huautla-Atenango sin duda ameritaba una fortificación militar por parte de los mexica, lo que explica ese topónimo.

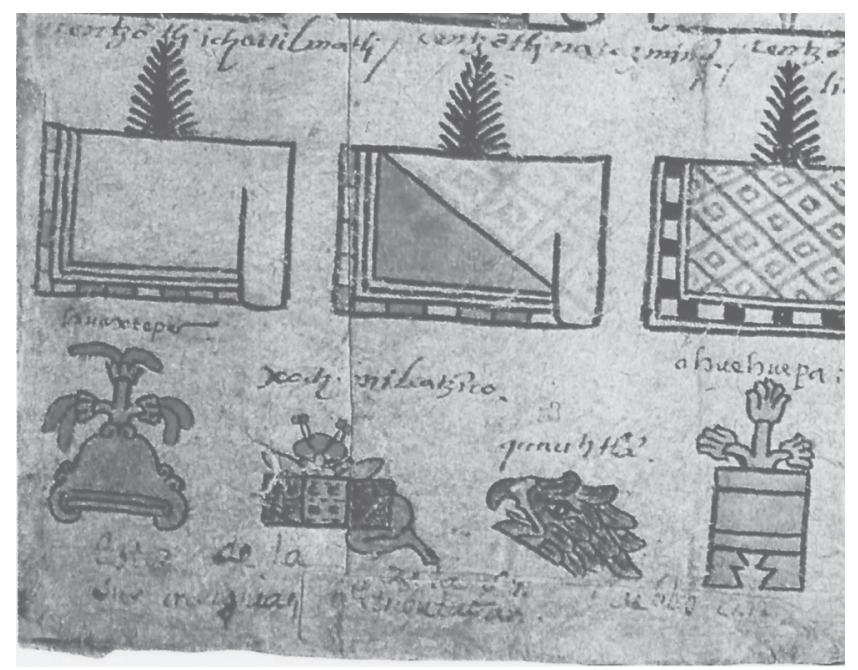

Pictografía del topónimo Cuauhtla (Morelos) en la Matrícula de tributos, lámina de Oaxtepec. En términos populares se traduce como "en el bosque", siendo que evidentemente refiere a los "águilas” o guerreros. Matrícula de tributos, lámina VII. 
Es un hecho que en los numerosos reinos o señoríos, que como un gran mosaico conformaban el llamado imperio mexica, los conquistadores hacían alianzas con la élite local. Sin duda la violencia de la guerra y la destrucción eran terribles, al igual que la amenaza de ejercerla y, además, las deportaciones y los sacrificios causaban pánico, pero, aunque tomaban prisioneros y sacrificaban a algunos señores, $\mathrm{y}$ les quitaban sus estancias (tierras con sus terrazgueros), por lo general los hueytlatoque del imperio se aliaban con algún heredero de uno de los linajes reconocidos localmente, los casaban con sus hijas y los dejaban gobernar en su reino. Así observamos en múltiples regiones, muy diversas, cómo la élite local asume y adquiere los títulos mexica de nobleza que todavía muestran en la documentación temprana del siglo xvi. En zona otomiana, chontal, coyxca, cholulteca o huasteca encontramos a los señores llamándose Huitznabua-Tecubtli, Tlacochcalca-Tecubtli, Acxotécatl, Azumpanecatl y demás nombres-cargo (o títulos), de la misma manera como, unas décadas más tarde, se llamarán regidor y fiscal, y varios "alcaldesme", adoptando en la misma localidad los prestigiosos títulos de la organización política introducida por los nuevos conquistadores. ${ }^{43}$

Así la toponimia, al igual que la antroponimia de señores vinculada a ella, también remite a la historia de la expansión mexica y puede proporcionar evidencias de traslados

${ }^{43}$ La presencia del título de Tlacochcalcatl-tecuhtli en los pueblos chontales del norte de Guerrero, así como en Cuauhnahuac, Oaxtepec y también en la zona otomiana, como Coatepec (Bateas) y muchos otros lugares, aún debe ser analizada cuidadosamente. Mentz, Cuaubnabuac, cap. 3, y pp. 130 y 166. Libro de las tasaciones, 1952. 
puntuales de población del altiplano en época mexica hacia zonas sobre las que callan las fuentes.

\section{CONCLUSIONES}

Hemos visto que la toponimia nos ayuda a rastrear determinados movimientos de población ocurridos en un pasado remoto. ${ }^{44}$ Ante el problema metodológico que enfrentan tanto historiadores como lingüistas, de documentar cuándo ocurrieron migraciones, cómo se generaron enclaves lingüísticos, o de explicar por qué existe la misma variante de una lengua en zonas muy alejadas entre sí (como en el caso del náhuatl), se han formulado algunas hipótesis sobre la antigüedad de ciertos nombres y la presencia de algunos topónimos para el caso del México antiguo en determinadas zonas y épocas.

Observamos: 1) la importancia universal del estudio de la toponimia para la reconstrucción del pasado y para comprobar movimientos de población que no se reportan en otras fuentes. Así, es de interés relacionar colonizaciones ocurridas desde el centro de México con la existencia de nombres como Tlatelolco en el valle de Toluca, o como Mexicapan en Oaxaca, junto a Xochimilco y Xalatlaco, también en ese valle oaxaqueño. Esos ejemplos de "topónimos-enclave de grupos fuereños” en determinadas circunstancias históricas

${ }^{44}$ Así los historiadores podrían incorporar el México antiguo a sus intereses, pues resulta incomprensible que la compleja economía prehispánica, por ejemplo, cuya organización fue tan importante para comprender la sociedad colonial, haya quedado excluida en trabajos generales, como la Historia económica general de México, de reciente aparición. Véase KunTz (coord.), Historia económica. 
deben considerarse con mayor detalle e interpretarse correctamente considerando muchas evidencias más del pasado del México antiguo.

2) Vimos, además, que algunos topónimos en náhuatl deben ser muy antiguos, por su estructura morfológica y su sufijo locativo - man. Observamos que ya no se usaba el locativo - man, -mani, en el siglo xvi o, como dirían los lingüistas, era una forma gramatical que "ya no era productiva”, por lo que proponemos como hipótesis que tales topónimos nos refieren a épocas remotas, a movimientos de grupos que hablaban un náhuatl arcaico.

3) Esto confirmaría aquellas hipótesis que sostienen que la lengua nahua se hablaba en el altiplano y en algunos puntos estratégicos del sur, incluyendo a Centroamérica, desde la época de Teotihuacan, y también nos permite observar cierta cronología de la introducción de las variantes de los diversos grupos de lengua nahua. Aunque el cuadro de topónimos en -man no es exhaustivo, estos nombres reflejan, pensamos, sobre todo contactos comerciales que perduraron a lo largo del tiempo, vinculados a colonizaciones permanentes relacionadas originalmente con el control de la sal y el comercio a distancia hacia el Golfo, al Istmo de Tehuantepec y por las costas del Pacífico hacia Centroamérica. Dicha actividad implicaba, en esa época, migración de familias enteras y contactos a través de generaciones, tanto de norte a sur como a la inversa. Con el paso del tiempo y las distintas influencias de las lenguas circundantes y los acontecimientos históricopolíticos regionales, surgieron distintas variantes de esa lengua antigua (como el pipil y el pochuteco), hoy tema de estudio especializado de numerosos lingüistas. 
4) Propusimos también la idea de que puntos estratégicos en determinadas rutas y zonas de guerra obtuvieron, en la época de expansión de la Triple Alianza, una toponimia específica. Podían ser tierras o estancias de cargo otorgadas a un alto funcionario militar, palacios del capitán general, posiblemente guarniciones de guerreros, arsenales o asentamientos fortificados. Esos enclaves mexica estratégicos podrían ser de gran interés para arqueólogos y así serían lugares que aportarían mucha información sobre el pasado prehispánico. Con los ejemplos específicos de los nombres de lugar, como Guautla (Cuauhtla, Huautla, Cuauhtecpan, etc.), Tlacochcalco (Tlacochixtlahuaca, Tlacochaca, etc.) y Acapetlahuaya, localizados en el mapa 2, se propone que esa toponimia quizás refleje la puntual y específica presencia militar de la Triple Alianza en regiones conquistadas o en rutas por controlar. Ahí coexistirían en algunos casos distintas variantes de la lengua náhuatl, siendo una de ellas, la más reciente, la del altiplano central o mexica.

Finalmente hay que tener conciencia de lo complejo del tema de la toponimia en lenguas indoamericanas y de que este ensayo deja muchísimas incógnitas pendientes sobre su origen y significado a lo largo del tiempo. Lo que quisiera subrayar es que el análisis de los nombres de lugar, lejos de ser solamente un tema de especialización lingüística, puede ser útil a los diferentes investigadores del pasado. El estudio de tiempos remotos, y en especial el de las complejas sociedades del México antiguo, podría invitar a una colaboración más cercana entre las diferentes disciplinas interesadas en el pasado de nuestra sociedad. Si bien cada una, por su naturaleza técnica específica, requiere de una metodología propia, no habrá que olvidar que la meta 
es la comprensión de la totalidad social humana, que sólo será posible alcanzar a partir de un verdadero diálogo interdisciplinario.

\section{REFERENCIAS}

Anders, Ferdinand, Maarten Jansen, Gabina Aurora Pérez JiméNez, "Introducción y explicación", en Anders, Jansen, Reyes GarCía (eds.), Crónica mixteca. El rey 8 venado, garra de jaguar y la dinastía de Teozacualco-Zaachila. Libro explicativo del llamado Códice Zouche-Nuttall, México, Graz, Sociedad Estatal Quinto Centenario, Akademische Druck und Verlagsanstalt, Fondo de Cultura Económica, 1992, pp. 9-66.

Bartholomew, Doris, "Intercambio lingüístico entre otomí y náhuatl”, en Estudios de Cultura Otopame, 2 (2000), pp. 189-201.

Beekes, Robert S.P., Comparative Indo-European Linguistics, an Introduction, Amsterdam Fhiladelfia, John Benjamins Publishing Company, 1995.

CAnger, Una, "Los dialectos del náhuatl de Guerrero", en Primer Coloquio de Arqueología y Etnohistoria del Estado de Guerrero, México, Instituto Nacional de Antropología e Historia, Gobierno del Estado de Guerrero, 1986, pp. 281-292.

CANGer, Una, "El nauatl urbano de Tlatelolco/ Tenochtitlan, resultado de convergencia entre dialectos. Con un esbozo brevísimo de la historia de los dialectos", en Estudios de Cultura Nábuatl, 42 (2011), pp. 243-258.

Canger, Una y Karen Dakin, "An Inconspicuous Basic Split in Náhuatl”, en Internacional Journal of American Linguistics, 5:4 (1985), pp. 258-261.

Carrasco, Pedro, Estructura político territorial del imperio tenochca. La Triple Alianza de Tenochtitlan, Texcoco y Tlacopan, México, El Colegio de México, Fondo de Cultura Económica, 1996. 
DAKIn, Karen, “Algunos documentos nahuas del sur de Mesoamérica”, en Dakin, Montes de Oca y Parodí (eds.), 2009, pp. 247-279.

DAKIN, Karen, “Observación y percepción del hombre de la naturaleza: evidencia del lenguaje”, en Mentz (ed.), 2012, pp.136-153.

DAKın, Karen, "El náhuatl del norte y sur de Guerrero: relaciones lingüísticas con el náhuatl de occidente y la costa del Pacífico”, en Pavía, Johnson y Von Mentz (coords.), 2016, pp. 91-110.

Dakin, K. M. Montes de Oca y C. Parodí (eds.), Visiones del encuentro de dos mundos en América: lengua, cultura, traducción y transculturación, México, Universidad Nacional Autónoma de México, 2009.

Dyckerhoff, Ursula, "Mexican Toponyms as a Source in Regional Ethnohistory”, en Harvey y Prem (eds.), 1984, pp. 229-252.

Dyckerhoff, Ursula y Hanns J. Prem, Toponyme und Ethnonyme im Klassischen Aztekischen, Berlín, Verlag von Flemming, 1990.

Escalante Hernández, Roberto, “Toponimia matlatzinca”, en Guzmán BetAncourt (coord.), 1987, pp. 163-166.

García Martínez, Bernardo y Gustavo Martínez Mendoza, Señoríos, pueblos y municipios. Banco preliminar de información, México, El Colegio de México, 2012.

Gerhard, Peter, Geografía histórica de la Nueva España, 1519-1821, México, Universidad Nacional Autónoma de México, 2000.

Guzmán Betancourt, Ignacio (coord.), De toponimia... y topónimos. Contribuciones al estudio de nombres de lugar provenientes de lenguas indígenas de México, México, Instituto Nacional de Antropología e Historia, Colección Divulgación, 1987.

Harvey, H.R. y Hanns J. Prem (eds.), Explorations in Ethnohistory. Indians of Central Mexico in the Sixteenth Century, Albuquerque, University of New Mexico Press, 1984. 
Hirth, Kenneth et al., Archaeological Research at Xochicalco; vol. 1 Ancient Urbanism at Xochicalco, the Evolution and Organization of a Pre-Hispanic Society; vol. 2 The Xochicalco Maping Project, Salt Lake City, University of Utah Press, 2000.

Kuntz, Sandra (coord.), Historia económica general de México. De la Colonia a nuestros días, México, El Colegio de México, 2010.

Libro de las tasaciones de pueblos de la Nueva España, siglo XVI, prólogo de Francisco González de Cossío, México, Archivo General de la Nación, 1952.

Longworth, Philip, The Making of Eastern Europe. From Prehistory to Postcommunism, Londres, Macmillan Press, 1997.

Manzanilla López, Rubén, La región arqueológica de la Costa Grande de Guerrero, México, Instituto Nacional de Antropología e Historia, 2008.

Matrícula de tributos. Original en el Museo Nacional de Antropología e Historia, México, cod. 35-52, Frances Berdan y Jaqueline de Durand (eds.), Graz, Austria, Akademische Druck und Verlagsanstalt, 1980.

Mentz, Brígida von, Cuaubnabuac 1450-1675. Su bistoria indígena y documentos en "mexicano". Cambio y continuidad de una cultura nabua, México, Miguel Ángel Porrúa, 2008.

Mentz, Brígida von (ed.), La relación hombre naturaleza, México, Centro de Investigación y Estudios Superiores en Antropología Social, Siglo Veintiuno editores, México, 2012.

Molina, fray Alonso de, Vocabulario en lengua castellana y mexicana y mexicana y castellana, México, Porrúa, 1992.

Muntzel, Martha C., “Topónimos ocuiltecos”, en Guzmán BetanCOURT (coord.), 1987, pp. 155-162.

Ochoa, Ángela, "Nombres de lugar en huasteco”, en Guzmán BeTANCOURT (coord.), 1987, pp. 135-145. 
Ochoa Salas, Lorenzo, Historia prebispánica de la Huasteca, México, Universidad Nacional Autónoma de México, 1979.

Pavía, María Teresa, Anne W. Johnson y Brígida von Mentz (coords.), Por el norte de Guerrero, México, Instituto Nacional de Antropología e Historia, 2016.

Quezada, Noemí, "Familia y grupos matlatzincas, siglos XVI-XVII. Una aproximación”, en Estudios de Cultura Otopame, año 2, 2:7 (2000), pp. 97-126.

Relación de minas de Taxco, en René AcuÑa (ed.), Relaciones geográficas del siglo XVI: México, México, unam, 1986, vol. 2, pp. 113-132.

Sepúlveda y Herrera, María Teresa, Los lienzos de San Juan Cuaubtla, Puebla, México, Miguel Ángel Porrúa, Conaculta, Instituto Nacional de Antropología e Historia, 2005.

Smith, E. Michael y Frances F. Berdan (eds.), The Postclassic Mesomaerican World, Salt Lake City, The University of Utah Press, 2003.

Stresser Péan, Guy, Viaje a la Huasteca con Guy Stresser-Pean, Guilhem Olivier (coord.), México, Fondo de Cultura Económica, Centro de Estudios Mexicanos y Centroamericanos, 2008.

TAnck de Estrada, Dorothy, Atlas ilustrado de los pueblos de indios, Nueva España, 1800, México, El Colegio de México, Comisión Nacional para el Desarrollo de los Pueblos Indígenas, El Colegio Mexiquense, Fomento Cultural Banamex, A. C., 2005.

Texeda, Gaspar de, "Informe del pueblo de Tlalcuzautitlan del vicario de todo el partido", en Papeles de Nueva España, Segunda Serie, Geografía y Estadística, vol. 5 Relaciones geográficas de la diócesis de Tlaxcala, Madrid, Estudio tipográfico Sucesores de Rivadeneyra, 1905, pp. 249-261.

Valiñas Coalla, Leopoldo, "El náhuatl de la periferia occidental y la costa del Pacífico", tesis de licenciatura, México, Escuela Nacional de Antropología e Historia, 1981. 
Valiñas Coalla, Leopoldo, "El matlatzinca y el ocuiloteco, ¿̇eran ya lenguas distintas en el siglo xvi?", en Estudios de Cultura Otopame, año 2, 2: 7 (2000), pp. $73-96$.

Valiñas Coalla, Leopoldo, "Historia lingüística: migraciones y asentamientos. Relaciones entre pueblos y lenguas”, en Rebeca BARRIGA VIllanueva y Pedro Martín Butragueño (coords.), Historia sociolingüistica de México, vol. 1. México prehispánico y colonial, México, El Colegio de México, 2010, pp. 97-159.

Van Doesburg, Sebastián, Códices Cuicatecos. Porfiriro Díaz y Fernández Leal, México, Miguel Ángel Porrúa, Gobierno del Estado de Oaxaca, 2001.

Wright Carr, David Charles, "Préstamos lingüísticos entre el otomí y el náhuatl”, en Ana María Salazar y Verónica Kugel (eds.), Homenaje a Yolanda Lastra. Coloquio Otopames. México, Universidad Iberoamericana, Universidad Nacional Autónoma de México, 2010.

Zantwijk, Rudolph van, The Aztec Arrangement: The Social History of Pre-Hispanic Mexico, Oklahoma, University of Oklahoma Press, 1985. 
